\title{
Two Sides to One Story-Aroma Chemical and Sensory Signature of Lugana and Verdicchio Wines
}

\author{
Davide Slaghenaufi (D), Giovanni Luzzini, Jessica Samaniego Solis (D), Filippo Forte and Maurizio Ugliano * \\ Department of Biotechnology, University of Verona, Villa Lebrecht, Via della Pieve 70, \\ 37029 San Pietro in Cariano, Italy; davide.slaghenaufi@univr.it (D.S.); giovanni.luzzini@univr.it (G.L.); \\ jessicaanahi.samaniegosolis@univr.it (J.S.S.); filippo.forte96@gmail.com (F.F.) \\ * Correspondence: maurizio.ugliano@univr.it
}

Citation: Slaghenaufi, D.; Luzzini, G.; Samaniego Solis, J.; Forte, F.; Ugliano, M. Two Sides to One Story-Aroma Chemical and Sensory Signature of Lugana and Verdicchio Wines. Molecules 2021, 26, 2127. https://doi.org/10.3390/molecules 26082127

Academic Editors: Franco Biasioli, Vittorio Capozzi, Iuliia Khomenko, Luigimaria Borruso and Patrick Silcock

Received: 11 February 2021

Accepted: 1 April 2021

Published: 7 April 2021

Publisher's Note: MDPI stays neutral with regard to jurisdictional claims in published maps and institutional affiliations.

Copyright: (c) 2021 by the authors. Licensee MDPI, Basel, Switzerland. This article is an open access article distributed under the terms and conditions of the Creative Commons Attribution (CC BY) license (https:/ / creativecommons.org/licenses/by/ $4.0 /)$.

\begin{abstract}
Lugana and Verdicchio are two Italian white wines with a Protected Designation of Origin (PDO) label. These two wine types are produced in different regions using the same grape variety. The aim of this work is to investigate the existence of volatile chemical markers that could help to elucidate differences between Lugana and Verdicchio wines both at chemical and sensory levels. Thirteen commercial wine samples were analyzed by Gas Chromatography-Mass Spectrometry (GC-MS), and 76 volatile compounds were identified and quantified. Verdicchio and Lugana had been differentiated on the basis of 19 free and glycosidically bound compounds belonging to the chemical classes of terpenes, benzenoids, higher alcohols, $\mathrm{C}_{6}$ alcohols and norisoprenoids. Samples were assessed by means of a sorting task sensory analysis, resulting in two clusters formed. These results suggested the existence of 2 product types with specific sensory spaces that can be related, to a good extend, to Verdicchio and Lugana wines. Cluster 1 was composed of six wines, 4 of which were Lugana, while Cluster 2 was formed of 7 wines, 5 of which were Verdicchio. The first cluster was described as "fruity", and "fresh/minty", while the second as "fermentative" and "spicy". An attempt was made to relate analytical and sensory data, the results showed that damascenone and the sum of 3 of esters the ethyl hexanoate, ethyl octanoate and isoamyl acetate, was characterizing Cluster 1 . These results highlighted the primary importance of geographical origin to the volatile composition and perceived aroma of Lugana and Verdicchio wines.
\end{abstract}

Keywords: Lugana; Verdicchio; wine aroma; chemical signature; sensory space

\section{Introduction}

The appellation of origin system is very important for the economic success of local wine on the international markets [1]. A particular added value is recognized for wines from specific geographical areas, which is reflected by the higher price that consumers are willing to pay for these wines [2]. Among the Protected Designation of Origin (PDO) specifications, grape varieties to be employed for winemaking and their area of origin are considered of primary importance.

However, individual varieties are grown in different parts of the world and are used in many PDO production regulations, giving wines with distinctive odor characters [3]. It is well known that grape geographical origin has an impact on wine chemical composition [4,5]. Also volatile compounds like terpenes, norisoprenoids, and fermentation-derived by-products (e.g., esters, alcohols) are affected by grape origin [6-10].

The effect of vineyard site on wines volatile compounds has been shown at various levels, from regional to single-vineyard scale $[4,7,11]$, and the impact on compounds such as terpenes, norisoprenoids, benzenoids and C6 alcohols is well known and somewhat expected [7,11-18]. Other studies indicate an influence of grape origin also on compounds primarily associated with fermentation $[10,19,20]$. Winemaking techniques also influence wine aroma [21], and grape aroma potential can be managed by applying adapted vinification protocols [3]. The typical odor characteristics of wines from a given PDO arise from complex interaction between 
grape variety, vineyard location and winemaking [22-24]. Combination of these factors lead to a pool of sensory characteristics leading to wine recognition, which can be easier when comparing wines from different varietal origin, while it is more complex when considering wines of the same variety but of different geographical origin.

Lugana and Verdicchio are two Italian PDO white wines. Lugana vineyards are located in the north of Italy, close to the Garda lake in an area spreading across the Veneto and Lombardia regions. Verdicchio is produced in Marche region, in Central Italy. The grapes used for the production of these wines are locally identified with different names, specifically "Trebbiano di Soave" or "Turbiana" for Lugana and "Verdicchio" for Verdicchio. However, although ampelographic descriptions suggested that these could be different grapes, genetic analysis indicated that they are identical varieties [25-27]. The different phenotypes observed do not appear indeed to be due to genetic differences, but to different biotypes of the same variety [25]. Few papers investigated the aroma of Verdicchio [28] and Lugana $[29,30]$. According to Carlin et al. [28], young Verdicchio wines were characterized by fruity, thiolic notes that during aging evolve towards balsamic and anise notes related to the presence of 3-methyl-2,4-nonanedione and methyl salicylate. Among the compounds more relevant for Lugana wine aroma, ethyl esters and norisoprenoids were found to play a major role [29]. Moreover, the varietal thiols 3-mercaptohexan-1-ol (3MH) and 3-mercaptohexyl acetate (3MHA), have been found in Lugana wines above their odor threshold [30]. A marker of this grape variety and so of both Lugana and Verdicchio wines, is methyl salicylate, a benzenoid characterized bybalsamic odors [28]. Lugana and Verdicchio exist on the market as two distinct products associated with individual PDOs. However, no comparison between the aromatic profiles of the two wines has been reported out so far. The question remains therefore open as to whether a chemical and sensory space specific of each one of these two PDOs really exists.

This research aimed at evaluating the existence of aromatic differences between Lugana and Verdicchio wines by means of volatile compounds analysis and sensory evaluation. The wines were collected at local retail shops in the province of Verona between April and June 2019. Volatile compounds were assessed by using multiple extraction techniques such as Solid Phase Extraction (SPE) and Solid Phase Microextraction (SPME) coupled with gas chromatography-mass spectrometry (GC-MS). Odor similarities/diversities between Lugana and Verdicchio were sensorially assessed by means of the sorting task methodology.

\section{Results and Discussion}

\subsection{Volatile Compounds in Lugana and Verdicchio Wine}

A total of 76 volatile compounds have been identified and quantified in wine samples, including 6 alcohols, $4 \mathrm{C}_{6}$ alcohols, 3 acetate esters, 8 ethyl esters, 3 acids, 23 terpenes, 3 sesquiterpenes, 7 norisoprenoids, 8 volatile sulfur compounds (VSC), 10 benzenoids and one further compound, furfural (Table 1). Twenty-four glycosidically-bound compounds were also quantified, 1 higher alcohol, $4 \mathrm{C}_{6}$ alcohols, 7 terpenols, 3 norisoprenoids, and 7 benzenoids.

Partial least square discriminant analysis (PLS-DA) was used to identify the chemical compounds that differentiated Lugana and Verdicchio wines. The first component (Component $115.6 \%$ ) allowed clear separation between the two wine categories (Figure 1), although the relatively high score obtained for the secondo component (Component $211 \%$ ) suggested significant intra-category variations, probably reflecting differences in grape compositions as well as winemaking techniques. In order to identify the compounds that contribute mostly to discriminate Lugana and Verdicchio wines, Variable Importance for the Projection (VIP) values were obtained from the PLS-DA model. Compounds with a VIP score greater than 1 were considered good candidates for Lugana and Verdicchio discrimination, and they were subjected to Mann-Whitney test with levels of significance of $\alpha=0.1$. The compounds with a VIP score > 1 but with a $p$ value $>0.1$ were not considered as Lugana and Verdicchio marker. Accordingly, a total of 20 parameters (either individual compounds or sum of compounds belonging to the same chemical class) were found to differentiate the two wine categories significantly (Table 2). 
Table 1. Volatile compounds mean concentration $(\mu \mathrm{g} / \mathrm{L})$ and standard deviation (in brackets) of Lugana and Verdicchio wines.

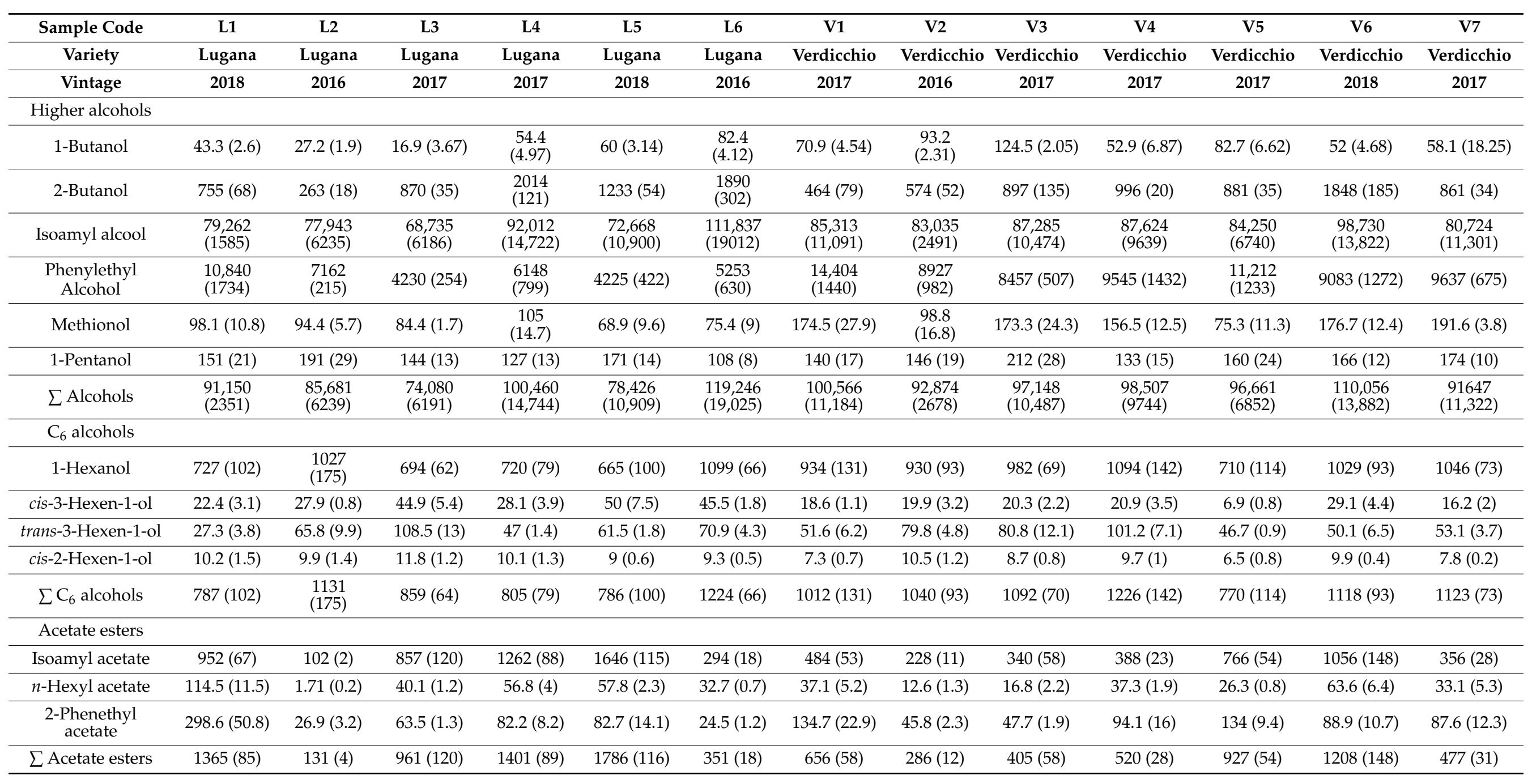


Table 1. Cont

\begin{tabular}{|c|c|c|c|c|c|c|c|c|c|c|c|c|c|}
\hline Sample Code & L1 & L2 & L3 & L4 & L5 & $\overline{L 6}$ & V1 & V2 & V3 & V4 & V5 & V6 & V7 \\
\hline Variety & Lugana & Lugana & Lugana & Lugana & Lugana & Lugana & Verdicchio & Verdicchio & Verdicchio & Verdicchio & Verdicchio & Verdicchio & Verdicchio \\
\hline Vintage & 2018 & 2016 & 2017 & 2017 & 2018 & 2016 & 2017 & 2016 & 2017 & 2017 & 2017 & 2018 & 2017 \\
\hline \multicolumn{14}{|l|}{ Ethyl esters } \\
\hline Ethyl butanoate & $254(2)$ & $134(1)$ & $248(7)$ & $250(20)$ & $253(40)$ & $333(30)$ & $232(3)$ & $279(12)$ & $209(8)$ & $297(7)$ & $327(14)$ & $333(17)$ & $132(3)$ \\
\hline $\begin{array}{c}\text { Ethyl } \\
\text { 2-methylbutyrate }\end{array}$ & $3.08(0.15)$ & $\begin{array}{l}1.18 \\
(0.18)\end{array}$ & $3.19(0.41)$ & $\begin{array}{c}6.91 \\
(0.62)\end{array}$ & $1.94(0.27)$ & $\begin{array}{c}9.49 \\
(1.33)\end{array}$ & $4.29(0.69)$ & $\begin{array}{l}5.59 \\
(0.84)\end{array}$ & $14.53(0.73)$ & $1.38(0.17)$ & $5.65(0.34)$ & $3.09(0.09)$ & $4.02(0.2)$ \\
\hline $\begin{array}{c}\text { Ethyl 3- } \\
\text { methylbutanoate }\end{array}$ & $5.34(0.69)$ & $\begin{array}{l}24.27 \\
(3.4)\end{array}$ & $16.45(0.82)$ & $\begin{array}{c}12.4 \\
(1.12)\end{array}$ & $4.43(0.31)$ & $\begin{array}{l}15.58 \\
(1.71)\end{array}$ & $9.85(0.49)$ & $\begin{array}{l}3.33 \\
(0.07)\end{array}$ & $23.07(2.54)$ & $2.62(0.39)$ & $11.11(1.44)$ & $10.36(0.93)$ & $6.95(0.14)$ \\
\hline $\begin{array}{c}\text { Ethyl 3- } \\
\text { hydroxybutyrate }\end{array}$ & $182(20)$ & $122(7)$ & $145(7)$ & $125(4)$ & $102(6)$ & $101(6)$ & $115(5)$ & $111(2)$ & $107(12)$ & $144(17)$ & $138(22)$ & $96(16)$ & $99(9)$ \\
\hline Ethyl hexanoate & $642(71)$ & $260(16)$ & $779(55)$ & $754(23)$ & $736(88)$ & $845(93)$ & $551(50)$ & $668(100)$ & $549(33)$ & $538(32)$ & 677 (115) & 705 (99) & $567(85)$ \\
\hline Ethyl octanoate & $990(129)$ & $435(26)$ & $648(26)$ & $591(35)$ & $740(81)$ & 894 (116) & $638(64)$ & $801(96)$ & $365(7)$ & $556(94)$ & 769 (131) & $652(104)$ & $562(96)$ \\
\hline Ethyl decanoate & $223(4)$ & $52(7)$ & $124(12)$ & $84(10)$ & $120(11)$ & $120(7)$ & $117(5)$ & $210(13)$ & $60(7)$ & $89(7)$ & $120(8)$ & $141(24)$ & 95 (13) \\
\hline Ethyl lactate & 1157 (197) & $\begin{array}{l}2073 \\
(187) \\
\end{array}$ & $3774(75)$ & $\begin{array}{l}14,745 \\
(1327)\end{array}$ & 2258 (203) & $\begin{array}{l}4712 \\
(236) \\
\end{array}$ & 4301 (473) & $\begin{array}{c}11,886 \\
(951)\end{array}$ & $\begin{array}{l}13,673 \\
(1641) \\
\end{array}$ & $8512(340)$ & $9328(1492)$ & 1354 (190) & $3460(346)$ \\
\hline$\sum$ Ethyl esters & 3455 (246) & $\begin{array}{l}3102 \\
(189)\end{array}$ & $5738(98)$ & $\begin{array}{l}16,568 \\
(1328)\end{array}$ & $4215(240)$ & $\begin{array}{l}7030 \\
(280)\end{array}$ & $5968(480)$ & $\begin{array}{c}13,965 \\
(961)\end{array}$ & $\begin{array}{l}15,001 \\
(1641)\end{array}$ & $\begin{array}{c}10,140 \\
(355)\end{array}$ & $\begin{array}{l}11375 \\
(1503)\end{array}$ & $3294(240)$ & $4926(369)$ \\
\hline \multicolumn{14}{|l|}{ Acids } \\
\hline $\begin{array}{l}\text { 3-Methylbutanoic } \\
\text { acid }\end{array}$ & $247(20)$ & $259(5)$ & $162(23)$ & $205(6)$ & $163(8)$ & $124(7)$ & $305(12)$ & $193(8)$ & $188(21)$ & $235(5)$ & $177(18)$ & $226(34)$ & $278(11)$ \\
\hline Hexanoic acid & $6282(691)$ & $\begin{array}{l}5655 \\
(735) \\
\end{array}$ & 4171 (459) & $\begin{array}{l}4222 \\
(253) \\
\end{array}$ & $4806(336)$ & $\begin{array}{l}6640 \\
(133) \\
\end{array}$ & $4406(441)$ & $\begin{array}{l}5035 \\
(705) \\
\end{array}$ & 3397 (272) & $5385(162)$ & $4245(340)$ & $4083(286)$ & $5305(849)$ \\
\hline Octanoic acid & $\begin{array}{l}10,053 \\
(1709)\end{array}$ & $\begin{array}{l}8636 \\
(691)\end{array}$ & 8437 (759) & $\begin{array}{l}7569 \\
(454)\end{array}$ & 8407 (1093) & $\begin{array}{c}9318 \\
(1025)\end{array}$ & 8452 (1183) & $\begin{array}{l}9137 \\
(365)\end{array}$ & $6767(1083)$ & 8385 (1258) & 8233 (1153) & 7986 (479) & 8596 (1375) \\
\hline$\sum$ Acids & $\begin{array}{l}16,581 \\
(1843)\end{array}$ & $\begin{array}{l}14,551 \\
(1009)\end{array}$ & $\begin{array}{c}12,770 \\
(887)\end{array}$ & $\begin{array}{l}11,997 \\
(520)\end{array}$ & $\begin{array}{l}13,377 \\
(1144)\end{array}$ & $\begin{array}{l}16,082 \\
(1034)\end{array}$ & $\begin{array}{l}13,163 \\
(1263)\end{array}$ & $\begin{array}{c}14,365 \\
(794)\end{array}$ & $\begin{array}{l}10,351 \\
(1116)\end{array}$ & $\begin{array}{l}14,005 \\
(1268)\end{array}$ & $\begin{array}{l}12,655 \\
(1202)\end{array}$ & $\begin{array}{c}12,294 \\
(559)\end{array}$ & $\begin{array}{l}14,179 \\
(1616)\end{array}$ \\
\hline \multicolumn{14}{|l|}{ Terpenes } \\
\hline 1,4-Cineole & $0.28(0.03)$ & $\begin{array}{c}0.72 \\
(0.03)\end{array}$ & $0.54(0.06)$ & $\begin{array}{c}0.41 \\
(0.01)\end{array}$ & $0.33(0.03)$ & $1.06(0)$ & $0.39(0.05)$ & $\begin{array}{c}0.81 \\
(0.04)\end{array}$ & $0.89(0)$ & $0.62(0)$ & $0.62(0.08)$ & $0.34(0.01)$ & $0.59(0.01)$ \\
\hline Limonene & $0.83(0.12)$ & $\begin{array}{c}0.35 \\
(0.04)\end{array}$ & $0.24(0)$ & $\begin{array}{c}0.44 \\
(0.07)\end{array}$ & $0.51(0.11)$ & $0.54(0)$ & $0.08(0.01)$ & $\begin{array}{c}0.26 \\
(0.06)\end{array}$ & $0.38(0)$ & $0.51(0)$ & $0.33(0)$ & $0.32(0.02)$ & $0.29(0.01)$ \\
\hline
\end{tabular}


Table 1. Cont.

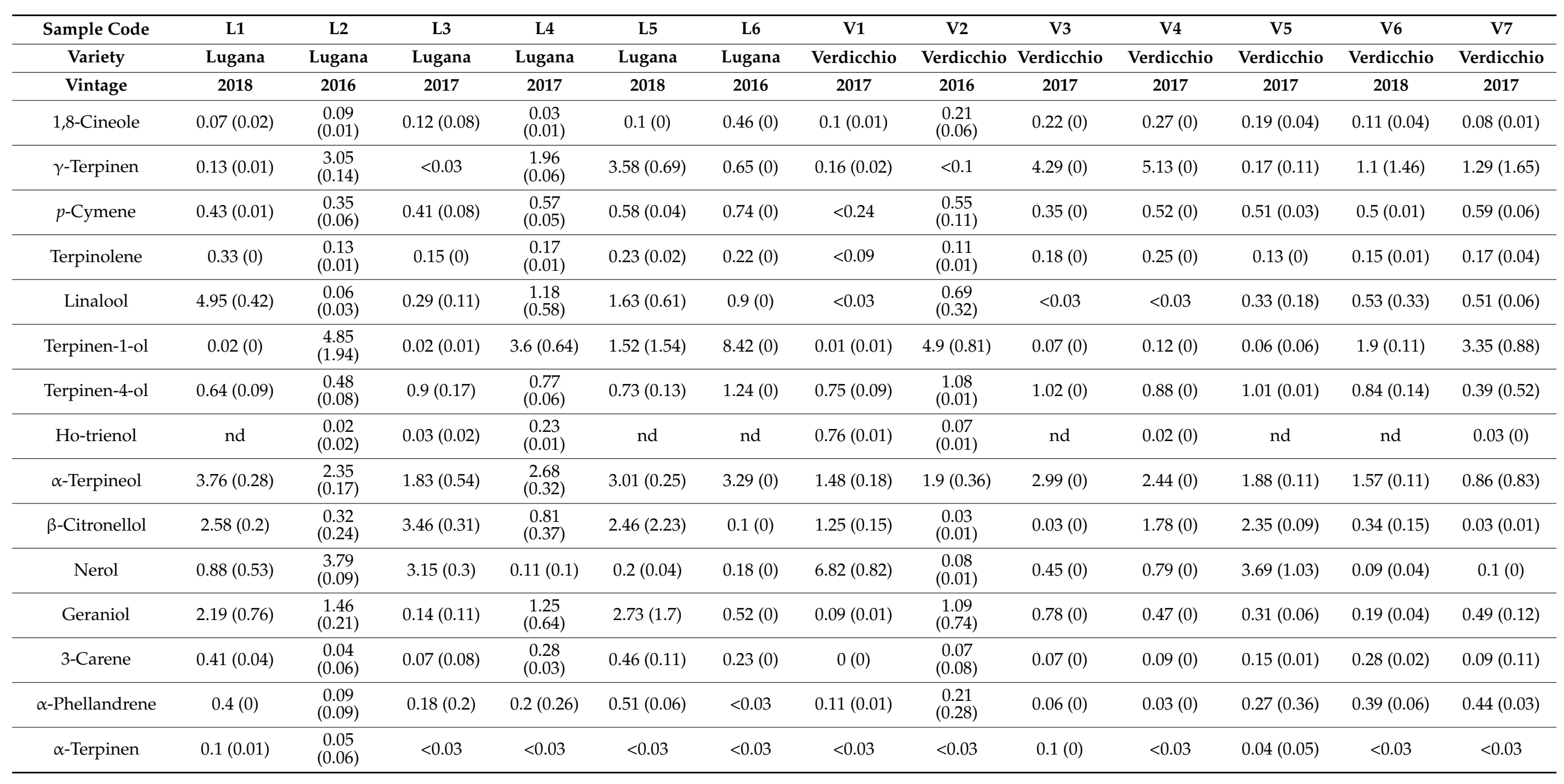


Table 1. Cont.

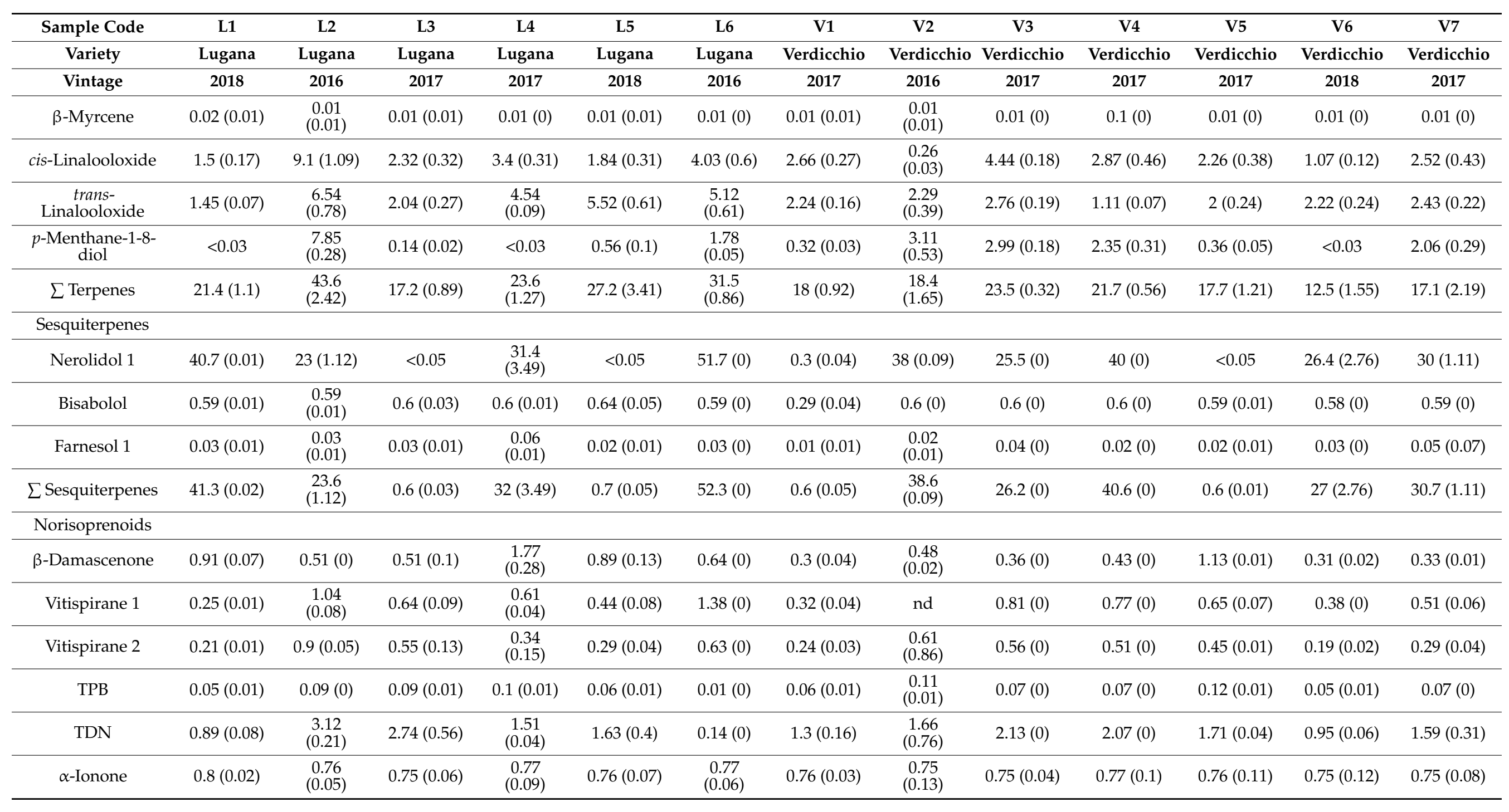


Table 1. Cont

\begin{tabular}{|c|c|c|c|c|c|c|c|c|c|c|c|c|c|}
\hline Sample Code & L1 & L2 & L3 & L4 & L5 & L6 & V1 & V2 & V3 & V4 & V5 & V6 & V7 \\
\hline Variety & Lugana & Lugana & Lugana & Lugana & Lugana & Lugana & Verdicchio & Verdicchio & Verdicchio & Verdicchio & Verdicchio & Verdicchio & Verdicchio \\
\hline Vintage & 2018 & 2016 & 2017 & 2017 & 2018 & 2016 & 2017 & 2016 & 2017 & 2017 & 2017 & 2018 & 2017 \\
\hline$\alpha$-Ionol & $0.76(0.04)$ & $\begin{array}{c}0.77 \\
(0.02)\end{array}$ & $0.75(0.04)$ & $\begin{array}{c}0.74 \\
(0.05)\end{array}$ & $0.75(0.03)$ & $\begin{array}{c}0.81 \\
(0.11)\end{array}$ & $0.76(0.04)$ & $\begin{array}{c}0.75 \\
(0.05)\end{array}$ & $0.75(0.04)$ & $0.76(0.08)$ & $0.75(0.03)$ & $0.75(0.05)$ & $0.79(0.06)$ \\
\hline $\begin{array}{l}\text { 3-Hydroxy- } \beta \text { - } \\
\text { damascone }\end{array}$ & nd & $0.01(0)$ & nd & $0.01(0)$ & nd & $0.01(0)$ & nd & $0.01(0)$ & $0.09(0.01)$ & $0.01(0)$ & nd & nd & $0.01(0)$ \\
\hline 3-Oxo- $\alpha$-ionol & $2.5(0.1)$ & $\begin{array}{c}3.11 \\
(0.06)\end{array}$ & $3.36(0.17)$ & $\begin{array}{c}2.01 \\
(0.14)\end{array}$ & $4.83(0.58)$ & $\begin{array}{l}5.98 \\
(0.66)\end{array}$ & $3.74(0.56)$ & $2.27(0.2)$ & $4.14(0.7)$ & $8.14(0.16)$ & $1.24(0.07)$ & $5.5(0.61)$ & $4.31(0.73)$ \\
\hline$\sum$ Norisoprenoids & $5.9(0.15)$ & $\begin{array}{c}8.37 \\
(0.22)\end{array}$ & $8.19(0.6)$ & $6.9(0.33)$ & $8.91(0.72)$ & $\begin{array}{c}8.35 \\
(0.67)\end{array}$ & $6.91(0.58)$ & $6.03(0.8)$ & $8.29(0.7)$ & $12.25(0.21)$ & $5.7(0.14)$ & $8.3(0.63)$ & $7.85(0.8)$ \\
\hline \multicolumn{14}{|l|}{$\begin{array}{l}\text { Volatile sulfur } \\
\text { compounds (VSC) }\end{array}$} \\
\hline 3-MH & $0.12(0.01)$ & $0.3(0.01)$ & $0.29(0.04)$ & $<0.05$ & $<0.05$ & $\begin{array}{c}0.12 \\
(0.01)\end{array}$ & $0.15(0.02)$ & $<0.05$ & $0.36(0.06)$ & $<0.05$ & $<0.05$ & $0.2(0.02)$ & $<0.05$ \\
\hline Carbon disulfide & $128.7(18.3)$ & $\begin{array}{c}50.2 \\
(13.6)\end{array}$ & $73.5(24.1)$ & $87.2(9.2)$ & $54.1(1.9)$ & $\begin{array}{c}92.7 \\
(25.3)\end{array}$ & $88(7.2)$ & $\begin{array}{l}115.4 \\
(12.5)\end{array}$ & $75.8(6.2)$ & $98.4(0.1)$ & $92.9(3.4)$ & $100.4(6.8)$ & $123.8(0.5)$ \\
\hline DMS & $1.69(0.04)$ & $1.7(0.04)$ & $1.46(0.07)$ & $\begin{array}{l}1.06 \\
(0.03)\end{array}$ & $0.98(0.02)$ & $\begin{array}{l}1.96 \\
(0.08)\end{array}$ & $0.21(0.03)$ & $3.1(0.02)$ & $1.66(0.01)$ & $1.4(0.04)$ & $0.38(0.01)$ & $0.69(0.01)$ & $1.16(0.02)$ \\
\hline DES & $1.18(0.06)$ & $\begin{array}{c}0.38 \\
(0.01)\end{array}$ & $0.69(0.03)$ & $\begin{array}{c}0.69 \\
(0.06)\end{array}$ & $0.63(0.05)$ & $\begin{array}{c}0.72 \\
(0.22)\end{array}$ & $0.6(0.13)$ & $1.1(0.06)$ & $0.79(0)$ & $0.55(0.01)$ & $0.67(0.01)$ & $0.86(0.09)$ & $0.77(0.18)$ \\
\hline DMDS & $<0.09$ & $<0.09$ & $<0.09$ & $<0.09$ & $<0.09$ & $<0.09$ & $<0.09$ & $<0.09$ & $<0.09$ & $<0.09$ & $<0.09$ & $<0.09$ & $<0.09$ \\
\hline Ethyl thioacetate & $1.07(0)$ & $\begin{array}{c}0.76 \\
(0.26) \\
\end{array}$ & $0.56(0.1)$ & $\begin{array}{c}0.81 \\
(0.04) \\
\end{array}$ & $0.63(0.3)$ & $\begin{array}{l}1.48 \\
(1.74)\end{array}$ & $0.86(0.4)$ & $\begin{array}{c}0.69 \\
(0.01)\end{array}$ & $0.6(0.33)$ & $0.36(0.03)$ & $0.7(0.1)$ & $1.03(0.07)$ & $0.98(0.3)$ \\
\hline DEDS & $<0.18$ & $<0.18$ & $<0.18$ & $<0.18$ & $<0.18$ & $<0.18$ & $<0.18$ & $<0.18$ & $<0.18$ & $<0.18$ & $<0.18$ & $<0.18$ & $<0.18$ \\
\hline DMTS & $<0.21$ & $<0.21$ & $<0.21$ & $<0.21$ & $<0.21$ & $<0.21$ & $<0.21$ & $<0.21$ & $<0.21$ & $<0.21$ & $<0.21$ & $<0.21$ & $<0.21$ \\
\hline$\sum \mathrm{VSC}$ & $132.8(18.3)$ & $\begin{array}{c}53.4 \\
(13.6) \\
\end{array}$ & $76.5(24.1)$ & $89.8(9.2)$ & $56.5(1.9)$ & $97(25.3)$ & $89.9(7.2)$ & $\begin{array}{l}120.4 \\
(12.5)\end{array}$ & $79.3(6.2)$ & $100.8(0.1)$ & $94.6(3.4)$ & $103.3(6.8)$ & $126.8(0.6)$ \\
\hline \multicolumn{14}{|l|}{ Benzenoids } \\
\hline Methyl salicylate & $19(1.13)$ & $37.7(0.2)$ & $20.9(3.44)$ & $\begin{array}{c}192 \\
(16.24)\end{array}$ & $26.7(4.5)$ & $49.8(0)$ & $7.6(0.91)$ & $\begin{array}{l}17.4 \\
(0.62)\end{array}$ & $13.8(0)$ & $26.5(0)$ & $19.1(0.85)$ & $56.4(2.4)$ & $11.4(0.69)$ \\
\hline 4-Ethyl guaiacol & $3.19(0.51)$ & $3.3(0.56)$ & $3.01(0.48)$ & $\begin{array}{l}3.39 \\
(0.51)\end{array}$ & $2.99(0.18)$ & $\begin{array}{l}3.07 \\
(0.09)\end{array}$ & $18.47(3.9)$ & $0(0)$ & $\begin{array}{c}103.2 \\
(12.39)\end{array}$ & $0(0)$ & $0(0)$ & $3.07(0.46)$ & $3.43(0.58)$ \\
\hline
\end{tabular}


Table 1. Cont.

\begin{tabular}{|c|c|c|c|c|c|c|c|c|c|c|c|c|c|}
\hline Sample Code & L1 & L2 & L3 & L4 & L5 & L6 & V1 & V2 & V3 & V4 & V5 & V6 & V7 \\
\hline Variety & Lugana & Lugana & Lugana & Lugana & Lugana & Lugana & Verdicchio & Verdicchio & Verdicchio & Verdicchio & Verdicchio & Verdicchio & Verdicchio \\
\hline Vintage & 2018 & 2016 & 2017 & 2017 & 2018 & 2016 & 2017 & 2016 & 2017 & 2017 & 2017 & 2018 & 2017 \\
\hline 4-Ethyl phenol & $3.44(0.1)$ & $\begin{array}{l}3.47 \\
(0.59)\end{array}$ & $3.46(0.28)$ & $\begin{array}{c}3.44 \\
(0.14)\end{array}$ & $3.43(0.58)$ & $\begin{array}{l}3.56 \\
(0.28)\end{array}$ & $3.45(0.1)$ & $\begin{array}{l}3.44 \\
(0.55)\end{array}$ & $3.46(0.28)$ & $3.44(0.48)$ & 3.47 (0.59) & $3.45(0.17)$ & $3.44(0.24)$ \\
\hline $\begin{array}{c}2,6- \\
\text { Dimethoxyphenol }\end{array}$ & $3.01(0.09)$ & $\begin{array}{c}3.05 \\
(0.31)\end{array}$ & $3.01(0.33)$ & $\begin{array}{c}3.22 \\
(0.29)\end{array}$ & $3.02(0.15)$ & $\begin{array}{c}3.04 \\
(0.18)\end{array}$ & $4.62(0.14)$ & $\begin{array}{c}3.03 \\
(0.15)\end{array}$ & $5.11(0.36)$ & $3.01(0.21)$ & $3.03(0.27)$ & $3.02(0.27)$ & $3.02(0.51)$ \\
\hline Vanillin & $<0.2$ & $\begin{array}{c}6.31 \\
(1.01)\end{array}$ & $4.33(0.17)$ & $\begin{array}{l}10.54 \\
(1.05)\end{array}$ & $6.66(0.73)$ & $<0.2$ & $18.89(0.38)$ & $\begin{array}{c}2.26 \\
(0.18)\end{array}$ & $3.87(0.12)$ & $4.59(0.6)$ & $10.47(1.05)$ & $4.97(0.5)$ & $3.59(0.29)$ \\
\hline Methyl vanillate & $7.77(0.47)$ & $\begin{array}{l}10.83 \\
(0.22) \\
\end{array}$ & 7.79 (1.32) & $\begin{array}{c}6.75 \\
(0.61)\end{array}$ & $8.69(0.87)$ & $\begin{array}{l}10.56 \\
(0.42)\end{array}$ & $6.1(0.49)$ & $\begin{array}{c}10.4 \\
(0.62)\end{array}$ & $6.52(0.65)$ & $6.61(0.93)$ & $6.83(0.41)$ & $7.27(0.87)$ & $5.57(0.95)$ \\
\hline Ethyl vanillate & $2.25(0.36)$ & $7.3(0.73)$ & $3.34(0.57)$ & $2(0.14)$ & $10.07(1.71)$ & $8.68(1.3)$ & $1.83(0.15)$ & $\begin{array}{l}2.47 \\
(0.12)\end{array}$ & $2.47(0.07)$ & $3.68(0.07)$ & $1.92(0.19)$ & $5.2(0.62)$ & $2.59(0.44)$ \\
\hline Vanillyl alcohol & $1.3(0.18)$ & $\begin{array}{c}1.35 \\
(0.23)\end{array}$ & $4.32(0.3)$ & $\begin{array}{c}7.49 \\
(0.75)\end{array}$ & $4.8(0.82)$ & $\begin{array}{l}11.37 \\
(1.14)\end{array}$ & $8.22(1.32)$ & $\begin{array}{l}1.49 \\
(0.13)\end{array}$ & $6.93(1.18)$ & $1.39(0.14)$ & $1.26(0.05)$ & $8.79(0.18)$ & $1.48(0.18)$ \\
\hline Benzaldehyde & $17.1(1)$ & $16.2(0.8)$ & $19.8(1.6)$ & $59.8(9)$ & $34.3(2.7)$ & $19.1(1.1)$ & $16.7(0.8)$ & $25.6(1.8)$ & $26.3(1.3)$ & $16.2(1)$ & $15.6(1.7)$ & $17.8(2.5)$ & $14.8(1.3)$ \\
\hline Benzyl Alcohol & $147(15)$ & $188(6)$ & $95(12)$ & $359(61)$ & $194(10)$ & $350(59)$ & $73(12)$ & 157 (19) & $201(30)$ & $109(18)$ & $72(3)$ & $165(28)$ & $81(2)$ \\
\hline$\sum$ Benzenoids & 204 (15) & $278(6)$ & $165(13)$ & $647(64)$ & $294(11)$ & $459(59)$ & $159(12)$ & $223(19)$ & $373(33)$ & $175(18)$ & $134(4)$ & $275(28)$ & $130(3)$ \\
\hline \multicolumn{14}{|l|}{$\begin{array}{l}\text { Glycosidically } \\
\text { bound } \\
\text { compounds }\end{array}$} \\
\hline 1-Hexanol & $11.3(0.45)$ & $\begin{array}{c}20.8 \\
(0.83)\end{array}$ & 9.7 (1.65) & $\begin{array}{c}13.7 \\
(1.51)\end{array}$ & $14.3(2)$ & $\begin{array}{l}39.5 \\
(2.77)\end{array}$ & $2.9(0.32)$ & $12.5(2)$ & $23.2(4)$ & $22.1(3.53)$ & $16.5(0.83)$ & $19.4(3.11)$ & $11.9(0.71)$ \\
\hline cis-3-Hexen-1-ol & $0.05(0)$ & $\begin{array}{c}0.04 \\
(0.01)\end{array}$ & $0.26(0.02)$ & $0.04(0)$ & $0.06(0)$ & $\begin{array}{c}0.43 \\
(0.06)\end{array}$ & $0.17(0.02)$ & $\begin{array}{c}0.42 \\
(0.05)\end{array}$ & $0.05(0.01)$ & $0.09(0.01)$ & $0.04(0)$ & $0.18(0.01)$ & $0.06(0.01)$ \\
\hline trans-3-Hexen-1-ol & $0.75(0.03)$ & $\begin{array}{c}4.32 \\
(0.52)\end{array}$ & $2.39(0.33)$ & $\begin{array}{c}2.06 \\
(0.25)\end{array}$ & $3.12(0.28)$ & $\begin{array}{l}5.99 \\
(0.12)\end{array}$ & $0.42(0.04)$ & $\begin{array}{c}1.07 \\
(0.07)\end{array}$ & $6.18(1.07)$ & $6.02(0.84)$ & $0.12(0.01)$ & $0.99(0.08)$ & $2.26(0.32)$ \\
\hline cis-2-Hexen-1-ol & $2.51(0.05)$ & $\begin{array}{l}13.62 \\
(1.5)\end{array}$ & $13.11(1.05)$ & $\begin{array}{l}13.78 \\
(0.55)\end{array}$ & $13.54(1.08)$ & $\begin{array}{l}12.91 \\
(1.94)\end{array}$ & $6.03(0.72)$ & $\begin{array}{c}1.17 \\
(0.13)\end{array}$ & $12.16(2.1)$ & $13.66(1.09)$ & $14.97(1.5)$ & $0.5(0.03)$ & $14.18(0.85)$ \\
\hline
\end{tabular}


Table 1. Cont

\begin{tabular}{|c|c|c|c|c|c|c|c|c|c|c|c|c|c|}
\hline Sample Code & L1 & L2 & L3 & L4 & L5 & L6 & V1 & V2 & V3 & V4 & V5 & V6 & V7 \\
\hline Variety & Lugana & Lugana & Lugana & Lugana & Lugana & Lugana & Verdicchio & Verdicchio & Verdicchio & Verdicchio & Verdicchio & Verdicchio & Verdicchio \\
\hline Vintage & 2018 & 2016 & 2017 & 2017 & 2018 & 2016 & 2017 & 2016 & 2017 & 2017 & 2017 & 2018 & 2017 \\
\hline cis-Linalool oxide & $4.87(0.58)$ & $\begin{array}{c}6.94 \\
(0.28)\end{array}$ & $5.7(0.63)$ & $1.52(0.2)$ & $6.63(0.4)$ & $\begin{array}{c}4.53 \\
(0.09)\end{array}$ & $0.97(0.16)$ & $\begin{array}{c}5.94 \\
(0.59)\end{array}$ & $1.24(0.21)$ & $3.85(0.19)$ & $0.11(0.02)$ & $0.76(0.02)$ & $0.52(0.09)$ \\
\hline $\begin{array}{l}\text { trans-Linalool } \\
\text { oxide }\end{array}$ & $5.23(0.31)$ & $\begin{array}{l}10.51 \\
(0.53)\end{array}$ & $7.47(0.22)$ & $\begin{array}{c}1.81 \\
(0.31)\end{array}$ & $9.5(0.48)$ & $4.97(0.8)$ & $0.97(0.14)$ & $\begin{array}{l}10.87 \\
(1.63)\end{array}$ & $3.02(0.52)$ & $5.98(0.66)$ & $0.09(0.01)$ & $0.79(0.07)$ & $0.16(0.01)$ \\
\hline Linalool & $12.21(0.61)$ & $0.04(0)$ & $0.1(0)$ & $\begin{array}{c}0.81 \\
(0.05)\end{array}$ & $1.92(0.17)$ & $0.08(0)$ & $2.13(0.17)$ & $\begin{array}{c}0.55 \\
(0.04)\end{array}$ & $3.02(0.52)$ & $2.39(0.05)$ & $31.53(2.21)$ & $0.48(0.01)$ & $0.09(0.01)$ \\
\hline$\alpha$-Terpineol & $25.1(0.8)$ & $6.2(0.3)$ & $17(2.4)$ & $3.5(0.5)$ & $31.1(3.7)$ & $6.2(0.7)$ & $17.2(2.2)$ & $26.8(4)$ & $19.2(3.3)$ & $16.1(1.6)$ & $13(0.8)$ & $68.9(2.8)$ & $27.9(3.1)$ \\
\hline$\beta$-Citronellol & $34.5(4.8)$ & $1.9(0.1)$ & $5.5(0.6)$ & $1(0.1)$ & $17.2(1.2)$ & $1.3(0.1)$ & $50.3(4)$ & $1.2(0.1)$ & $4.1(0.7)$ & $3.7(0.4)$ & $32.1(5.5)$ & $7.1(0.9)$ & $5(0.1)$ \\
\hline Methyl salicylate & $229(23)$ & $317(25)$ & $142(16)$ & $132(21)$ & $238(19)$ & $355(53)$ & $93(14)$ & $62(6)$ & $19(3)$ & $172(12)$ & $149(25)$ & $472(47)$ & $165(20)$ \\
\hline Nerol & $11.3(1.5)$ & $25.8(1)$ & $17.2(2.2)$ & $8.5(0.4)$ & $14.2(14.6)$ & $4.3(0.3)$ & $5.6(0.6)$ & $4.7(0.1)$ & $24.3(4.2)$ & $16.3(2.1)$ & $17.1(2.6)$ & $9.9(9.5)$ & $14.3(2.1)$ \\
\hline Geraniol & $19.3(1.6)$ & $60.1(4.8)$ & $41.6(2.5)$ & $12.6(0.4)$ & $22.9(45.3)$ & $21.8(1.1)$ & $28.5(368.9)$ & $100(7)$ & $28.2(35.9)$ & $29(4.4)$ & $24.8(4)$ & $232.5(37.2)$ & $55.5(6.7)$ \\
\hline Benzyl Alcohol & $7189(863)$ & $\begin{array}{l}2474 \\
(198) \\
\end{array}$ & $2510(326)$ & $622(12)$ & $6711(671)$ & $988(168)$ & $8150(245)$ & $\begin{array}{l}5424 \\
(271) \\
\end{array}$ & 1848 (319) & $1628(195)$ & $2143(214)$ & $\begin{array}{c}10,893 \\
(436)\end{array}$ & $2871(287)$ \\
\hline$\alpha$-Ionol & $1.03(0.15)$ & $0.8(0.07)$ & $0.79(0.1)$ & $0.74(0.1)$ & $0.97(0.04)$ & $\begin{array}{c}0.76 \\
(0.13)\end{array}$ & $1.8(0.16)$ & $\begin{array}{l}1.24 \\
(0.17)\end{array}$ & $1.02(0.18)$ & $0.76(0.05)$ & $0.86(0.08)$ & $1.57(0.25)$ & $0.79(0.08)$ \\
\hline $\begin{array}{l}\text { Phenylethyl } \\
\text { Alcohol }\end{array}$ & $1796(198)$ & $692(111)$ & $919(138)$ & $190(6)$ & $1599(64)$ & $254(8)$ & $4020(80)$ & $\begin{array}{l}2605 \\
(234)\end{array}$ & $6620(142)$ & $681(75)$ & $995(60)$ & $3219(64)$ & $1572(236)$ \\
\hline $\begin{array}{c}\text { 2,6- } \\
\text { Dimethoxyphenol }\end{array}$ & $3.15(0.5)$ & $\begin{array}{c}3.05 \\
(0.31)\end{array}$ & $3.05(0.27)$ & $\begin{array}{c}3.01 \\
(0.51)\end{array}$ & $3.09(0.4)$ & $\begin{array}{c}3.04 \\
(0.18)\end{array}$ & $3.47(0.52)$ & $3.6(0.14)$ & $3.75(0.65)$ & $3.1(0.06)$ & $3.12(0.31)$ & $3.78(0.3)$ & $3.1(0.47)$ \\
\hline $\begin{array}{l}\text { 3-Hydroxy- } \beta \text { - } \\
\text { damascone }\end{array}$ & $2.62(0.42)$ & $\begin{array}{c}0.71 \\
(0.08)\end{array}$ & $1.21(0.19)$ & $\begin{array}{c}0.22 \\
(0.01)\end{array}$ & $1.97(0.04)$ & $\begin{array}{c}0.23 \\
(0.04)\end{array}$ & $0.72(0.02)$ & $\begin{array}{l}4.76 \\
(0.76)\end{array}$ & $3.17(0.55)$ & $0.74(0.01)$ & $1.02(0.07)$ & $4.3(0.56)$ & $1.77(0.19)$ \\
\hline Vanillin & $18.1(2.4)$ & $2.4(0.4)$ & $6.3(1.1)$ & $4.7(0.6)$ & $9.3(1.3)$ & $2.3(0.1)$ & $24.5(4.2)$ & $4.9(0.2)$ & $5(0.9)$ & $2.3(0.2)$ & $10(1)$ & $4.5(0.5)$ & $21.5(1.5)$ \\
\hline Methyl vanillate & $42.7(4.7)$ & $19.7(3.2)$ & $23.9(2.2)$ & $4.6(0.1)$ & 34.7 (3.1) & $7.8(0.4)$ & $108.2(15.2)$ & $\begin{array}{l}150.3 \\
(12)\end{array}$ & $24.8(4.3)$ & $13.5(0.8)$ & $21.1(2.5)$ & $92.4(2.8)$ & $26.5(1.3)$ \\
\hline Ethyl vanillate & $26.9(4)$ & $17.9(2.7)$ & $10.4(0.2)$ & $3.7(0.1)$ & $33.6(0.7)$ & $5.3(0.5)$ & $55.2(5.5)$ & $\begin{array}{c}147 \\
(16.2)\end{array}$ & $7.4(1.3)$ & $6.5(0.6)$ & $21.5(1.7)$ & $43.6(1.3)$ & 31.9 (1.9) \\
\hline 3-Oxo- $\alpha$-ionol & $91.5(11)$ & $37.4(2.2)$ & $55(6.1)$ & $7.6(1.1)$ & $90.8(8.2)$ & $14(1.8)$ & $361.1(57.8)$ & $\begin{array}{l}172.2 \\
(15.5)\end{array}$ & $180.9(31.2)$ & $36.5(4.8)$ & $50.2(3.5)$ & $214(23.5)$ & $126.8(2.5)$ \\
\hline Vanillyl alcohol & $193.9(29.1)$ & $1.8(0.1)$ & $36.2(5.8)$ & $13.1(0.3)$ & $67.1(5.4)$ & $14(2.1)$ & $469.8(32.9)$ & $\begin{array}{l}157.1 \\
(26.7)\end{array}$ & $131.9(22.8)$ & $45.2(6.8)$ & $81.5(13.9)$ & $364.8(29.2)$ & $126.4(17.7)$ \\
\hline
\end{tabular}


Table 2. Variable of Importance for the Projection (VIP) score, statistical significance, level of significance $\left(p<0.1^{*} ; p<0.05^{* *} ; p<0.01^{* * *}\right)$.

\begin{tabular}{|c|c|c|c|}
\hline & VIP Component 1 & $p$-Value & Sign \\
\hline cis-3-Hexen-1-ol & 2.0616 & 0.01 & $* * *$ \\
\hline Methionol & 2.0096 & 0.032 & $* *$ \\
\hline 2-Phenylethyl alcohol & 1.9485 & 0.022 & $* *$ \\
\hline Bound 2,6-Dimethoxy phenol & 1.8326 & 0.01 & $* * *$ \\
\hline Bound cis-Linaloloxide & 1.814 & 0.022 & $* *$ \\
\hline trans-Linaloloxide & 1.7723 & 0.024 & $* *$ \\
\hline$\alpha$-Terpineol & 1.7117 & 0.046 & $* *$ \\
\hline Bound 3-Oxo- $\alpha$-ionol & 1.6867 & 0.046 & ** \\
\hline$\sum$ of Terpenes & 1.6739 & 0.046 & ** \\
\hline Geraniol & 1.6189 & 0.063 & * \\
\hline Benzyl alcohol & 1.5696 & 0.086 & * \\
\hline Bound 2-Phenylethyl alcohol & 1.5631 & 0.063 & * \\
\hline 1-Butanol & 1.5193 & 0.086 & * \\
\hline Bound Vanillyl alcohol & 1.4933 & 0.032 & ** \\
\hline cis-2-Hexen-1-ol & 1.4775 & 0.116 & \\
\hline Ethyl vanillate & 1.4483 & 0.198 & \\
\hline 3-Carene & 1.4357 & 0.252 & \\
\hline Limonene & 1.4263 & 0.1 & * \\
\hline Methyl vanillate & 1.4196 & 0.032 & ** \\
\hline$\beta$-Damascenone & 1.396 & 0.022 & $* *$ \\
\hline Linalool & 1.3485 & 0.063 & * \\
\hline Bound Methyl vanillate & 1.3406 & 0.153 & \\
\hline$\alpha$-Ionone & 1.3361 & 0.199 & \\
\hline Bound $\alpha$-Ionol & 1.3297 & 0.152 & \\
\hline Bound trans-Linalooloxide & 1.3033 & 0.116 & \\
\hline 1-Hexanol & 1.2344 & 0.253 & \\
\hline Terpinolene & 1.1962 & 0.199 & \\
\hline DMTS & 1.1892 & nc & \\
\hline Bound 3-Hydroxy- $\beta$-damascone & 1.1848 & 0.153 & \\
\hline Hexanoic acid & 1.184 & 0.253 & \\
\hline Carbon disulfide & 1.1347 & 0.116 & \\
\hline Bound Ethyl vanillate & 1.1087 & 0.153 & \\
\hline Methyl salycilate & 1.1044 & 0.063 & * \\
\hline$\sum$ of VSC & 1.095 & 0.153 & \\
\hline$\sum$ of Acids & 1.0874 & 0.253 & \\
\hline Bound $\alpha$-Terpineol & 1.0837 & 0.199 & \\
\hline Isoamyl acetate & 1.0804 & 0.391 & \\
\hline$\sum$ of C6 alcohols & 1.0526 & 0.475 & \\
\hline 2,6-Dimethoxy phenol & 1.0507 & 0.664 & \\
\hline$\sum$ of acetate esters & 1.0459 & 0.317 & \\
\hline Bound Geraniol & 1.0447 & 0.086 & * \\
\hline Benzaldehyde & 1.0439 & 0.153 & \\
\hline 3-Methylbutanoic acid & 1.0202 & 0.253 & \\
\hline
\end{tabular}

nc: not calculable

Among these, higher content of total terpenes was observed in Lugana wines compared to Verdicchio. The most abundant monoterpene alcohols, namely linalool, $\alpha-$ terpineol, and geraniol, were all detected in significantly higher concentrations in Lugana. Several cyclic terpenes with a $p$-methane structure were also identified in different samples, reaching concentrations of several $\mu \mathrm{g} / \mathrm{L}$ such as in the case of terpinen-4-ol and $p$-menthane-1,8-diol. The bi-cyclic terpenes 1,4- and 1,8-cineole were also observed, with the former attaining in some samples concentrations higher than the reported threshold of $0.63 \mu \mathrm{g} / \mathrm{L}$ [31]. These compounds have recently attracted considerable attention for their possible contribution to the eucalyptus and balsamic attributes of red wines [31-33], but to our knowledge, their occurrence in white wines is not well documented. Interestingly, with the exclusion of two outliers (L2 and V7), 1,4-cineole as well as the $\sum 1,4$-cineole and 
1,8-cineole were well correlated with terpinen-4-ol $\left(\mathrm{R}^{2}=0.89\right.$ for both correlations if $\mathrm{L} 2$ and V7 were excluded), and 1,4-cineole was also correlated with $p$-menthane-1,8-diol $\left(R^{2}=0.73\right.$ if L2 and L6 were excluded). These data confirm the recent observations of Slaghenaufi and Ugliano (2018) [33] concerning the relationship existing between different cyclic terpenes under the acidic conditions of wine, highlighting the possible role of terpinen-4-ol and $p$-menthane-1,8-diol as possible precursors to cineoles, although the presence of some outliers indicate that other precursor might exist. Additionally, a good correlation was also observed between 1,4- and 1,8-cineole $\left(R^{2}=0.63\right)$ across the entire dataset, which is of particular interest considering that these two compounds can act synergistically to favor the expression of hay and eucalyptus attributes [30]. The pool of cyclic terpenes detected could be potentially involved in the balsamic odor notes often perceived in aged samples of these wines [28]. Moreover, terpenes have been reported to have olfactive synergic and additive effects in wine and spirits matrix [34], which should also be considered. A number of different factors determine wine terpene content. Terpenes are produced in grapes through both the 1-deoxy-d-xylulose-5-phosphate/methylerythritol phosphate (DOXP/MEP) pathway and the mevalonic acid (MVA) pathway [35], and in the case of non-aromatic grapes such as Trebbiano they are found mostly in glycosidically bound form, which are then released by yeast during fermentation [36]. The different concentrations of terpenes could be due to viticultural and environmental factors [37-39], so that they can be also good markers of geographical wine origin [11].

\section{Scores Plot}

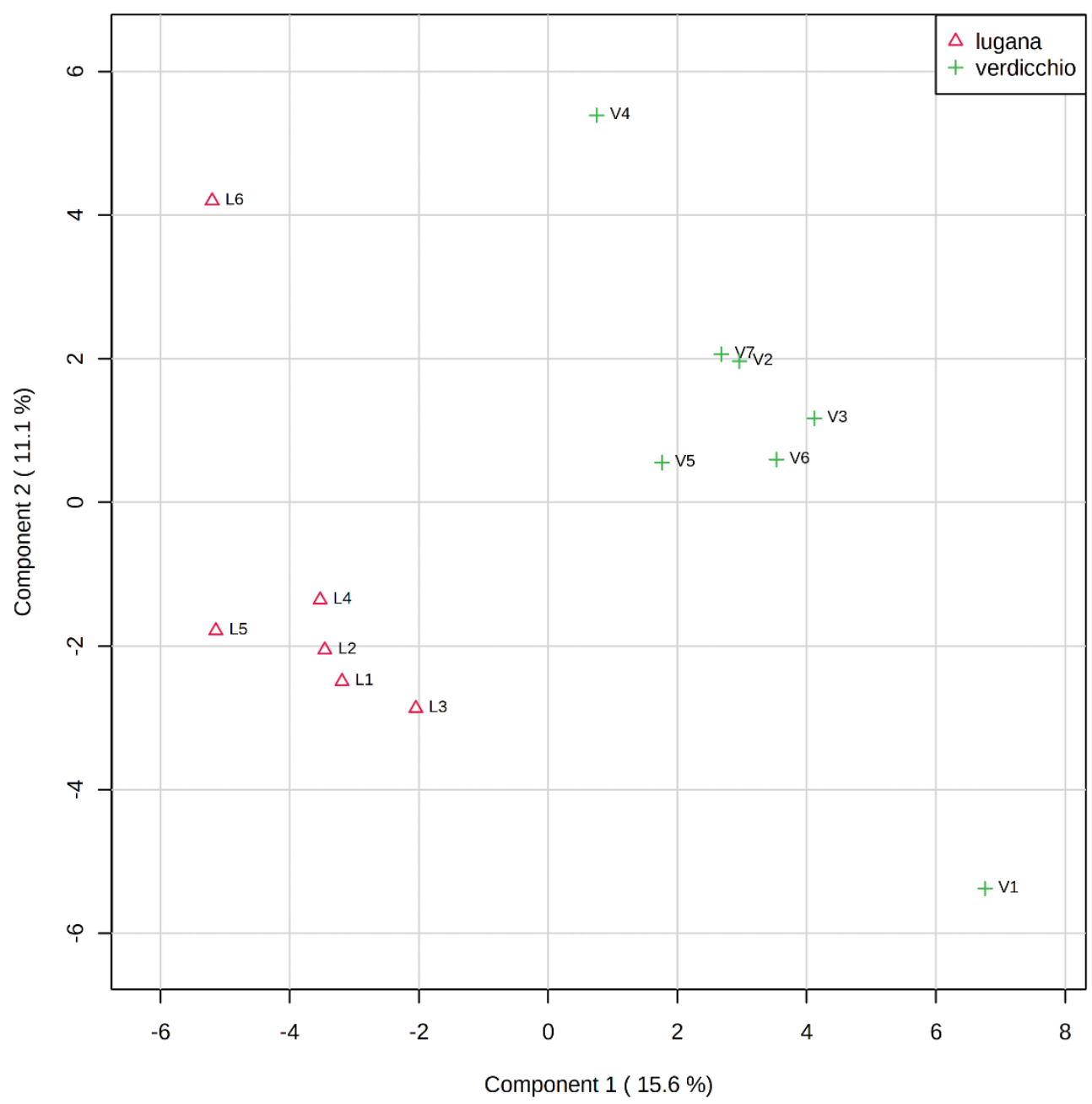

Figure 1. Partial least squares discriminant analysis (PLS-DA) scatterplot of Lugana and Verdicchio wines samples. 
Lugana wines were characterized by higher concentration of $\beta$-damascenone. Cooked apple, quince aroma notes characterize this molecule and its formed mostly during fermentation by acid- or yeast-mediated hydrolysis of multiple precursors [40,41]. Environmental and agronomical factors could influence the precursors level in grapes and consequently, the $\beta$-damascenone concentration in wine $[7,42-44]$. The concentration of $\beta$-damascenone largely exceed the odor threshold of $0.05 \mu \mathrm{g} / \mathrm{L}$ [45] in all wine samples, contributing to Verdicchio and Lugana aroma. Another norisprenoid differentiating the wines was 3 -oxo- $\alpha$-ionol in the form of glycosidic precursor. During aging, this compound undergoes acid hydrolysis releasing the aglycone moiety [46], as well as acid rearrangements products [33], leading to the formation of megastigmatrienone isomers associated to tobacco aroma in aged wines and spirits $[47,48]$. The concentration of bound 3 -oxo- $\alpha$-ionol found in Verdicchio wines could be a reservoir of aroma potentially characterizing aged Verdicchio wines.

Occurrence of relatively high levels of free and glycosidically-bound methyl salicylate were also observed, in agreement with recent observations concerning this compound's high content and its glycosidic precursors in Trebbiano di Soave and Verdicchio wines [28,29,49]. Methyl salicylate is characterized by a distinctive mint, wintergreen aroma [50], and could further contribute to the balsamic character of these wines. Lugana wines showed a significantly higher average concentration $(55.6 \mu \mathrm{g} / \mathrm{L})$ of metyl salicylate compared to Verdicchio wines $(21.7 \mu \mathrm{g} / \mathrm{L})$ with a significance level of $p=0.073$. Other benzenoids were also detected, with Lugana showing higher content of methyl vanillate and benzyl alcohol, and Verdicchio showing higher concentration in glycoconjugated precursors of vanillyl alcohol, phenylethyl alcohol and 2,6-dimethoxyphenol. Benzenoids are an important class of compounds that could participate to the oaky, spicy and medicinal character of wine [51]. As wines were not stored in barrels, the differences observed are probably related to characteristics of the grapes and/or levels of precursor extraction occurring during winemaking.

The $\mathrm{C}_{6}$ alcohols are related to herbaceous odors and they are formed during berry crushing by enzymatic oxidation of grape unsaturated fatty acids [52]. The amount of $\mathrm{C}_{6}$ alcohols in wines could be related to different factors like grape variety $[53,54]$, maturity [55], as well as technological factors such as timing of $\mathrm{SO}_{2}$ addition [56] and duration of pre-fermentative skin contact [57]. The lower content of cis-3-hexenol in Verdicchio wines could be due to the combination of one or more of these factors.

Ubiquitous fermentative compounds contributing to fruity and vinous attributes such as esters, alcohols, and fatty acids were detected and quantified. In some cases, they were found to statistically discriminate the two wine types in the case of methionol and phenylethyl alcohol, occurring at higher concentrations in Verdicchio.

Finally, sulfur compounds and terpenes were two groups of volatiles that appeared to characterize the volatile fraction of Lugana and Verdicchio. Among sulfur compounds, the polyfunctional thiol 3-mercaptohexanol (3-MH), contributing to passionfruit/grapefruit attributes and previously identified among the most potent aroma compounds present in wine [58] was observed. Occurrence of this compound in Lugana wines has been previously reported, in particular in association with reductive winemaking conditions [30]. GC-Olfactometry experiments indicated that certain Verdicchio wines contain 3-MH [28], although quantitative data are not present in the literature. The concentrations observed suggest that this compound contributes to Lugana and Verdicchio's aroma, although differences observed across the two wine types were not statistically significant. Other sulfur compounds were also detected, some of which rarely reported in white wines, including several disulfides and one trisulfide, typically associated with onion smells. The most abundant of these was carbon disulfide, previously reported in different wines [59].

As the sample set used in the study included wines of different vintages, the possibile influence of vintage was also considered. The volatile compounds influenced by vintage were hexanoic acid $(p$-value $=0.096), p$-menthane-1,8-diols $(p$-value $=0.093)$, TPB $(p$-value $=0.078)$, diethyl sulfide $(p$-value $=0.088)$, as well as glycosylated cis-2-hexen-1-ol 
$(p$-value $=0.067)$, and 2,6-dimethoxyphenol $(p$-value $=0.063)$. None of these compounds was among those responsible for Lugana and Verdicchio differentiation.

\subsection{Sensory Sorting Task and Relationship between Odor Characteristics and Volatile Composition}

Sensory evaluation of the samples was carried out by means of a sorting task aiming at grouping samples based on their odor similarities. This approach has been successfully used to establish the existence of odor profiles that can be associated to specific variables, including grape variety, yeast strain and wine quality grade [60-62]. In the present study, we were interested in clarifying whether two wines with a well-defined product space, such as Verdicchio and Lugana, produced in two different regions of Italy using a single grape variety, also possessed a defined olfactory space. Data obtained from the sorting task analysis were submitted to hierarchical cluster analysis (HCA). Results (Figure 2) showed that wines were divided into two different clusters. Cluster 1 was formed by 6 wines, 4 of which were Lugana, while Cluster 2 was formed by 5 Verdicchio wines and 2 Lugana. Cluster 1 was described mostly as "fruity" and "fresh/minty", while Cluster 2 was described as "fermentative" and "spicy". Although odor clusters did not correspond perfectly to wine type, they reflected wine types to a large extent. These observations indicate that a specific olfactory space exists for each one of the two clusters. This could be associated, to a good extent, with one of the two wine types investigated. The notion of a sensory space that can be linked explicitly to individual wine types (e.g., wines from specific varieties, appellations, or geographical origin), has been discussed by a number of authors, in relationship to the concepts of typicality, regional/geographical identity, terroir [63-65]. Our data confirm other authors' findings concerning the existence of specific sensory spaces for single product types, although the presence of outliers reflecting specific viticultural and enological scenarios has to be taken into account $[63,66,67]$.

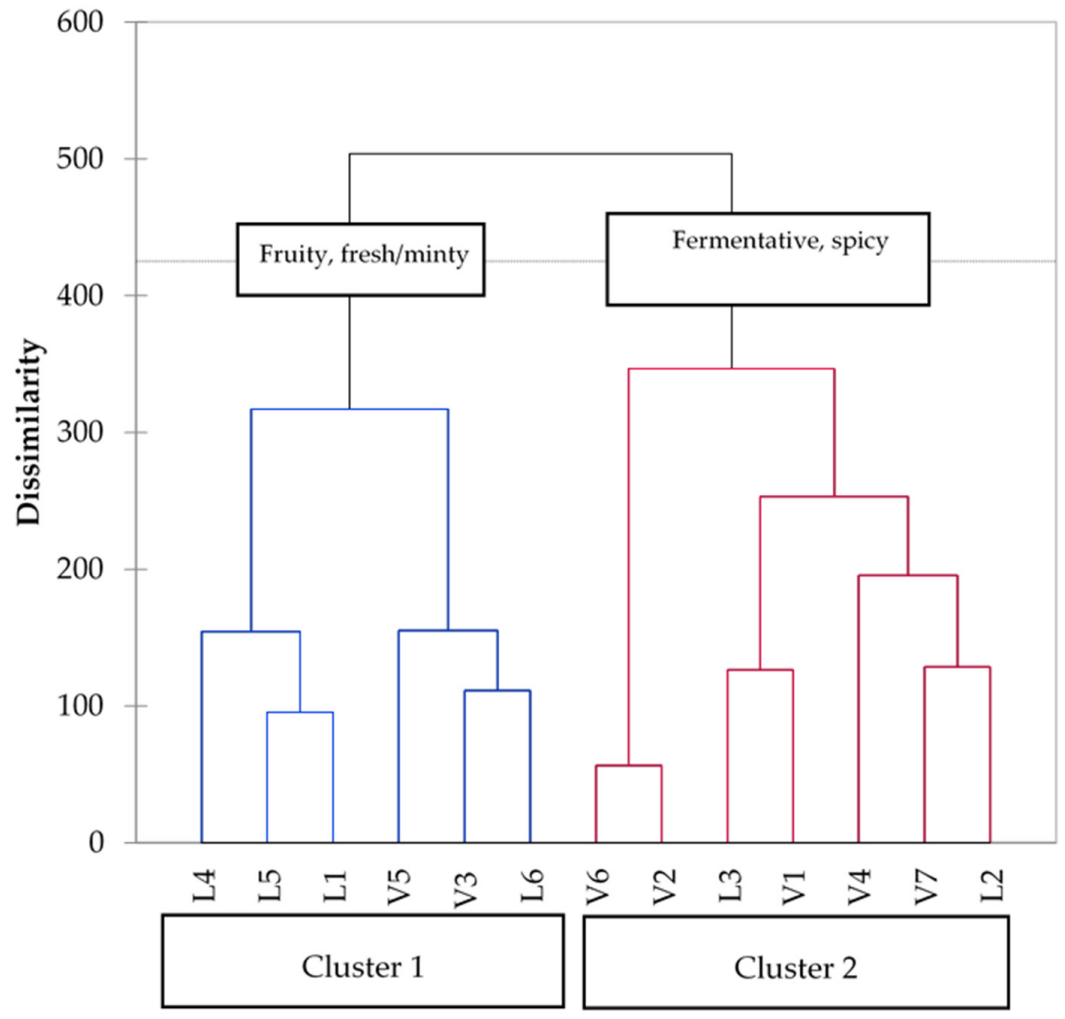

Figure 2. Dendrogram illustrating the results of Lugana and Verdicchio wines sorting task. The dashed line indicates the significance threshold. The blue lines represent Cluster $\mathbf{1}$, the red lines represent Cluster 2. 
The volatile compounds characterizing the two clusters were then identified. Twelve volatile compounds showed significant differences $(\alpha=0.1)$ across the two clusters. Cluster 1 was characterized by a higher concentration of 3-carene, limonene, $\alpha$-terpineol, and $\beta$-damascenone, while Cluster 2 was characterized by 2-butanol, methionol, 3-methyl butanoic acid, terpinolene, geraniol, linalool, ho-trienol, $\alpha$-terpinen. Moreover, the sum of $\mathrm{C}_{6}$ alcohols was found in significantly higher concentration in wines of Cluster $2(\alpha=0.1)$ (Table 3).

Table 3. Concentration ( $\mu \mathrm{g} / \mathrm{L})$ of free volatile compounds in Cluster 1 and Cluster 2 wine samples. Odor threshold, mean, standard deviation (SD), statistical significance, level of significance $\left(p<0.1^{*} ; p<0.05^{* *} ; p<0.01^{* * *}\right)$.

\begin{tabular}{|c|c|c|c|c|c|c|c|c|}
\hline & \multicolumn{3}{|l|}{ Cluster 1} & \multicolumn{5}{|c|}{ Cluster 2} \\
\hline & \multicolumn{2}{|c|}{ Mean $(\mu \mathrm{g} / \mathrm{L})$} & \multirow[t]{2}{*}{ SD } & \multicolumn{2}{|c|}{ Mean $(\mu g / L)$} & SD & $p$-Value & Level \\
\hline & & & & & & & & \\
\hline 1-Butanol & 75 & \pm & 29 & 53 & \pm & 26 & 0.234 & \\
\hline 2-Butanol & 1278 & \pm & 547 & 840 & \pm & 514 & 0.100 & * \\
\hline Isoamyl alcool & 87,886 & \pm & 13,492 & 83,158 & \pm & 9204 & 0.628 & \\
\hline Phenylethyl alcohol & 7689.2 & \pm & 2940.9 & 8998.3 & \pm & 3056.6 & 0.534 & \\
\hline Methionol & 99 & \pm & 39 & 140 & \pm & 45 & 0.089 & * \\
\hline 1-Pentanol & 155 & \pm & 36 & 156 & \pm & 21 & 0.945 & \\
\hline$\sum$ Alcohols & 97,182 & \pm & 13,312 & 93,345 & \pm & 11,482 & 0.731 & \\
\hline \multicolumn{9}{|l|}{$\mathrm{C}_{6}$ alcohols } \\
\hline 1-Hexanol & 817.3 & \pm & 178.1 & 964.9 & \pm & 133.4 & 0.295 & \\
\hline cis-3-Hexen-1-ol & 28.9 & \pm & 16.2 & 25.4 & \pm & 9.9 & 0.534 & \\
\hline trans-3-Hexen-1-ol & 55.7 & \pm & 19.3 & 72.9 & \pm & 24.3 & 0.234 & \\
\hline cis-2-Hexen-1-ol & 9 & \pm & 1 & 10 & \pm & 2 & 0.534 & \\
\hline$\sum$ C6 alcohols & 911 & \pm & 196 & 1073 & \pm & 117 & 0.097 & * \\
\hline \multicolumn{9}{|l|}{ Acetate esters } \\
\hline Isoamyl acetate & 876.7 & \pm & 526.5 & 496 & \pm & 342.1 & 0.295 & \\
\hline n-Hexyl acetate & 50.8 & \pm & 35.3 & 32.2 & \pm & 20.1 & 0.628 & \\
\hline 2-Phenethyl acetate & 112 & \pm & 99 & 77 & \pm & 35 & 0.945 & \\
\hline$\sum$ Acetate esters & 1039 & \pm & 580 & 606 & \pm & 375 & 0.234 & \\
\hline \multicolumn{9}{|l|}{ Ethyl esters } \\
\hline Ethyl butanoate & 270.9 & \pm & 48.7 & 236.5 & \pm & 77.7 & 0.534 & \\
\hline Ethyl 2-methylbutyrate & 6.9 & \pm & 4.6 & 3.2 & \pm & 1.6 & 0.138 & \\
\hline Ethyl 3-methylbutanoate & 12 & \pm & 7 & 11 & \pm & 8 & 0.628 & \\
\hline Ethyl 3-hydroxybutanoate & 126 & \pm & 31 & 119 & \pm & 20 & 0.836 & \\
\hline Ethyl hexanoate & 700 & \pm & 102 & 581 & \pm & 168 & 0.234 & \\
\hline Ethyl octanoate & 725 & \pm & 223 & 613 & \pm & 113 & 0.295 & \\
\hline Ethyl decanoate & 121 & \pm & 56 & 118 & \pm & 49 & 0.945 & \\
\hline Ethyl lactate & 7646 & \pm & 5819 & 5052 & \pm & 3785 & 0.445 & \\
\hline$\sum$ Ethyl esters & 9607 & \pm & 5554 & 6733 & \pm & 3953 & 0.295 & \\
\hline \multicolumn{9}{|l|}{ Acids } \\
\hline 3-Methylbutanoic acid & 184 & \pm & 41 & 237 & \pm & 49 & 0.089 & * \\
\hline Hexanoic acid & 4932 & \pm & 1272 & 4863 & \pm & 635 & 0.945 & \\
\hline Octanoic acid & 8391 & \pm & 1180 & 8518 & \pm & 345 & 0.628 & \\
\hline$\sum$ Acids & 13,507 & \pm & 2411 & 13,618 & \pm & 873 & 0.731 & \\
\hline \multicolumn{9}{|l|}{ Terpenes } \\
\hline 1,4-Cineole & 0.6 & \pm & 0.32 & 0.57 & \pm & 0.17 & 0.976 & \\
\hline Limonene & 0.5 & \pm & 0.18 & 0.29 & \pm & 0.13 & 0.015 & $* *$ \\
\hline 1,8-Cineole & 0.18 & \pm & 0.16 & 0.14 & \pm & 0.07 & 0.945 & \\
\hline$\gamma$-Terpinen & 1.79 & \pm & 1.8 & 1.54 & \pm & 1.91 & 0.628 & \\
\hline$p$-Cymene & 0.53 & \pm & 0.13 & 0.44 & \pm & 0.15 & 0.423 & \\
\hline Terpinolene & 0.21 & \pm & 0.07 & 0.14 & \pm & 0.06 & 0.073 & * \\
\hline Linalool & 1.5 & \pm & 1.79 & 0.3 & \pm & 0.28 & 0.079 & * \\
\hline Terpinen-1-ol & 2.28 & \pm & 3.31 & 2.16 & \pm & 2.22 & 0.945 & \\
\hline
\end{tabular}


Table 3. Cont

\begin{tabular}{|c|c|c|c|c|c|c|c|c|}
\hline \multirow[b]{3}{*}{ Terpinen-4-ol } & \multicolumn{3}{|c|}{ Cluster 1} & \multicolumn{5}{|c|}{ Cluster 2} \\
\hline & \multicolumn{2}{|c|}{ Mean $(\mu \mathrm{g} / \mathrm{L})$} & \multirow{2}{*}{$\frac{\text { SD }}{0.23}$} & \multicolumn{2}{|c|}{ Mean $(\mu g / L)$} & \multirow{2}{*}{$\begin{array}{c}\text { SD } \\
0.25\end{array}$} & \multirow{2}{*}{$\frac{p \text {-Value }}{0.534}$} & \multirow[t]{2}{*}{ Leve } \\
\hline & 0.9 & \pm & & 0.76 & \pm & & & \\
\hline Ho-trienol & 0.04 & \pm & 0.09 & 0.13 & \pm & 0.28 & 0.061 & * \\
\hline$\alpha$-Terpineol & 2.93 & \pm & 0.63 & 1.77 & \pm & 0.54 & 0.008 & $* *$ \\
\hline$\beta$-Citronellol & 1.39 & \pm & 1.21 & 1.03 & \pm & 1.26 & 0.505 & \\
\hline Nerol & 0.92 & \pm & 1.38 & 2.12 & \pm & 2.58 & 0.945 & \\
\hline Geraniol & 1.29 & \pm & 0.97 & 0.56 & \pm & 0.52 & 0.087 & * \\
\hline 3-Carene & 0.27 & \pm & 0.15 & 0.09 & \pm & 0.09 & 0.024 & $* *$ \\
\hline$\alpha$-Phellandrene & 0.24 & \pm & 0.19 & 0.21 & \pm & 0.15 & 0.836 & \\
\hline$\alpha$-Terpinen & 0.05 & \pm & 0.04 & 0.01 & \pm & 0.02 & 0.097 & * \\
\hline$\beta$-Myrcene & 0.01 & \pm & 0 & 0.02 & \pm & 0.04 & 0.204 & \\
\hline cis-Linalooloxide & 2.91 & \pm & 1.22 & 2.97 & \pm & 2.87 & 0.731 & \\
\hline trans-Linalooloxide & 3.57 & \pm & 1.72 & 2.7 & \pm & 1.75 & 0.534 & \\
\hline$p$-Menthane-1,8-diol & 0.9 & \pm & 1.2 & 2.3 & \pm & 2.8 & 0.443 & \\
\hline$\sum$ Terpenes & 24.1 & \pm & 4.8 & 21.2 & \pm & 10.2 & 0.138 & \\
\hline \multicolumn{9}{|l|}{ Sesquiterpenes } \\
\hline Nerolidol & 24.89 & \pm & 21.22 & 22.52 & \pm & 16.43 & 0.836 & \\
\hline Bisabolol & 0.6 & \pm & 0.02 & 0.55 & \pm & 0.12 & 0.469 & \\
\hline Farnesol & 0 & \pm & 0 & 0 & \pm & 0 & 0.337 & \\
\hline$\sum$ Sesquiterpenes & 25.5 & \pm & 21.2 & 23.1 & \pm & 16.5 & 0.628 & \\
\hline \multicolumn{9}{|l|}{ Norisoprenoids } \\
\hline$\beta$-Damascenone & 0.95 & \pm & 0.48 & 0.41 & \pm & 0.1 & 0.013 & $* *$ \\
\hline Vitispirane 1 & 0.69 & \pm & 0.39 & 0.52 & \pm & 0.34 & 0.534 & \\
\hline Vitispirane 2 & 0.41 & \pm & 0.16 & 0.47 & \pm & 0.25 & 0.976 & \\
\hline TPB & 0.06 & \pm & 0.04 & 0.08 & \pm & 0.02 & 0.720 & \\
\hline $\mathrm{TDN}$ & 1.33 & \pm & 0.71 & 1.92 & \pm & 0.78 & 0.366 & \\
\hline$\alpha$-Ionone & 0.77 & \pm & 0.02 & 0.76 & \pm & 0.01 & 0.114 & \\
\hline$\alpha$-Ionol & 0.76 & \pm & 0.03 & 0.76 & \pm & 0.01 & 0.487 & \\
\hline 3-Hydroxy- $\beta$-damascone & 0.02 & \pm & 0.04 & 0.01 & \pm & 0.01 & 0.883 & \\
\hline 3-Oxo- $\alpha$-ionol & 3.45 & \pm & 1.82 & 4.35 & \pm & 1.95 & 0.534 & \\
\hline$\sum$ Norisoprenoids & 7.34 & \pm & 1.37 & 8.27 & \pm & 1.95 & 0.534 & \\
\hline \multicolumn{9}{|l|}{$\begin{array}{l}\text { Volatile sulfur compounds } \\
\text { (VSC) }\end{array}$} \\
\hline 3-MH & 0.1 & \pm & 0.1 & 0.1 & \pm & 0.1 & 0.534 & \\
\hline Carbon disulfide & 88.55 & \pm & 24.49 & 92.83 & \pm & 25.06 & 0.731 & \\
\hline DMS & 1.29 & \pm & 0.59 & 1.39 & \pm & 0.91 & 0.945 & \\
\hline DES & 0.78 & \pm & 0.2 & 0.71 & \pm & 0.23 & 0.628 & \\
\hline DMDS & 0.02 & \pm & 0.02 & 0.02 & \pm & 0.02 & 0.971 & \\
\hline Ethyl thioacetate & 0.88 & \pm & 0.34 & 0.75 & \pm & 0.24 & 0.628 & \\
\hline DEDS & 0.01 & \pm & 0.01 & 0.01 & \pm & 0.01 & 0.336 & \\
\hline DMTS & 0 & \pm & 0 & 0 & \pm & 0 & 0.860 & \\
\hline$\sum \mathrm{VSC}$ & 91.7 & \pm & 25 & 95.9 & \pm & 25.3 & 0.731 & \\
\hline \multicolumn{9}{|l|}{ Benzenoids } \\
\hline Methyl salicylate & 53.41 & \pm & 69.07 & 25.4 & \pm & 16.9 & 0.534 & \\
\hline 4-Ethyl guaiacol & 19.31 & \pm & 41.12 & 4.47 & \pm & 6.36 & 0.864 & \\
\hline 4-Ethyl phenol & 3.47 & \pm & 0.05 & 3.45 & \pm & 0.01 & 0.948 & \\
\hline 2,6-Dimethoxyphenol & 3.41 & \pm & 0.84 & 3.25 & \pm & 0.6 & 0.457 & \\
\hline Vanillin & 5.26 & \pm & 4.78 & 6.42 & \pm & 5.64 & 0.908 & \\
\hline Methyl vanillate & 7.85 & \pm & 1.55 & 7.8 & \pm & 2.06 & 0.836 & \\
\hline Ethyl vanillate & 4.57 & \pm & 3.76 & 3.77 & \pm & 1.89 & 0.760 & \\
\hline Vanillyl alcohol & 5.5 & \pm & 3.9 & 3.9 & \pm & 3.3 & 0.945 & \\
\hline Benzaldehyde & 29 & \pm & 17 & 18 & \pm & 4 & 0.181 & \\
\hline Benzyl Alcohol & 220.4 & \pm & 113.3 & 124 & \pm & 45.4 & 0.138 & \\
\hline$\sum$ Benzenoids & 131.5 & \pm & 87.4 & 76.6 & \pm & 20 & 0.445 & \\
\hline Furfural & 28.5 & \pm & 28.2 & 23.1 & \pm & 20.6 & 0.731 & \\
\hline
\end{tabular}


The potential impact of these markers on perceived aroma was assessed considering their odor active value $(\mathrm{OAV})$, expressed as the ratio between the concentration and the olfactory threshold of each compound (Table 4).

Compounds with an odor active value higher than $1(\mathrm{OAV} \geq 1)$ were considered to have an impact on wine aroma. Ten compounds showed an OAV $\geq 1$ in all samples, namely isoamyl alcohol, ethyl butanoate, isoamyl acetate, ethyl hexanoate, ethyl octanoate, 3 -methyl butanoic acid, hexanoic acid, octanoic acid, $\beta$-damascenone, $\alpha$-ionone. Moreover, 9 compounds showed an OAV $\geq 1$ in at least one sample, namely phenylethyl alcohol, ethyl 3-methyl butanoate, ethyl decanoate, 1,4-cineole, TPB, TDN, 4-ethylguaiacol, methyl salicylate and 3-MH.

Among the compounds with an $\mathrm{OAV} \geq 1$, only $\beta$-damascenone and 3-methyl butanoic acid were significantly different in the two clusters suggesting their contribution to the observed aromatic differences. In particular, $\beta$-damascenone may contribute to the fruity attribute of Cluster 1 while the 3-methyl butanoic acid to the fermentative aroma of Cluster 2 wines. Considering that wine aroma is the results from complex interactions between volatile compounds often acting through $[68,69]$, volatile compounds were grouped into aromatic series according to their odor descriptors and chemical family. The series used were fruity, stewed apple/quince, grapefruit, floral, fresh/minty, vinous, spicy, green, reductive, fermentative and evolutive. The series were made in order to obtain a better representation of aroma descriptors commonly used during wine tasting, also considering the aroma families proposed by Ferreira et al., (2010) [70]. The score attributed to each series was calculated as the sum of the average OAV of each volatile compound within that series (Table 4). Significant differences were observed only in three aromatic series: fruity, stewed apple/quince, and floral (Table 5). The stewed apple series included $\beta$ damascenone, that as described previously, was significantly higher in Cluster 1 . The fruity series was formed by ethyl and acetate esters and it was found to have higher values in Cluster 1. Analyzing the data it can be observed that the concentration, and therefore the OAVs, of the individual esters was not significantly different among clusters, but the sum of esters (and therefore the corresponding score of the aromatic series), was significantly higher in Cluster 1 ( $p$-value $=0.063)$. This indicates that esters, and in particular the most potent ethyl hexanoate, ethyl octanoate and isoamyl acetate, could play a role in the aroma of Cluster 1 wines by a synergic and/or additive effect. These two first series, the fruity and the stewed apple/quince, may explain the fruity notes used by the panel to describe Cluster 1, considering that $\beta$-damascenone has been shown to enhance wine perceived fruitiness [70].

The attributes most cited in Cluster 2 were fermentative and spicy. Contrary to what was expected, the aromatic series fermentative, vinous, and spicy were not significantly different between the two clusters. In fact, the aromatic series "vinous" and "fermentative" showed similar values. However, it is however possible that he descriptor "fermentative", characterizing Cluster 2, was not related to a higher concentration of some compounds, but to a lower content of compounds with a fruity character (esters, norisoprenoid), so that the generic fermentative character was more expressed in Cluster 2 [70].

The aromatic series spicy and fresh/minty were not significantly different among the two clusters. Consequently, it was not possible to determine the group of compounds potentially contributing to the "spicy" and "fresh / minty" sensory attributes, although compounds such as cineoles and methyl salicylate are characterized by minty and balsamic odors. It is also possible that other molecules contributed to this odor note, and they were not measured in the present study, for example, 2,4-methylnonanedione reported in Verdicchio wines by Carlin et al. (2019) [28]. 
Table 4. Odour threshold ( $\mu \mathrm{g} / \mathrm{L})$, aromatic series, and odour activity values of some volatile compounds of wine samples.

\begin{tabular}{|c|c|c|c|c|c|c|c|c|c|c|c|c|c|c|c|}
\hline & & & L1 & L4 & L5 & L6 & V3 & V5 & V1 & V2 & V4 & V6 & V7 & L2 & L3 \\
\hline & $\begin{array}{c}\text { Odor } \\
\text { Threshold } \\
(\mu \mathrm{g} / \mathrm{L})\end{array}$ & $\begin{array}{l}\text { Aromatic } \\
\text { Series } 16\end{array}$ & $\underset{1}{\text { Cluster }}$ & $\underset{1}{\text { Cluster }}$ & $\begin{array}{c}\text { Cluster } \\
1\end{array}$ & $\underset{1}{\text { Cluster }}$ & $\underset{1}{\text { Cluster }}$ & $\begin{array}{c}\text { Cluster } \\
1\end{array}$ & $\begin{array}{c}\text { Cluster } \\
2\end{array}$ & $\begin{array}{c}\text { Cluster } \\
2\end{array}$ & $\begin{array}{c}\text { Cluster } \\
2\end{array}$ & $\begin{array}{c}\text { Cluster } \\
2\end{array}$ & $\underset{2}{\text { Cluster }}$ & $\begin{array}{c}\text { Cluster } \\
2\end{array}$ & $\underset{2}{\text { Cluster }}$ \\
\hline Ethyl butanoate & $20^{1}$ & a & 12.68 & 12.52 & 12.65 & 16.63 & 10.43 & 16.34 & 11.58 & 13.97 & 14.84 & 16.66 & 6.62 & 6.71 & 12.40 \\
\hline Ethyl 3-metilbutanoate & $3^{1}$ & $\begin{array}{l}a \\
a\end{array}$ & 0.27 & 0.62 & 0.22 & 0.78 & 1.15 & 0.56 & 0.49 & 0.17 & $\begin{array}{l}14.04 \\
0.13\end{array}$ & 0.52 & $\begin{array}{l}0.02 \\
0.35\end{array}$ & 1.21 & 0.82 \\
\hline Isoamyl acetate & $30^{1}$ & $\begin{array}{l}a \\
a\end{array}$ & 31.74 & 42.07 & 54.86 & 9.78 & 11.34 & 25.54 & 16.14 & 7.60 & 12.95 & 35.19 & 11.87 & $\begin{array}{l}1.21 \\
3.40\end{array}$ & 28.58 \\
\hline Ethyl hexanoate & $14^{1}$ & $\mathrm{a}$ & 45.84 & 53.86 & 52.58 & 60.37 & 39.23 & 48.34 & 39.38 & 47.71 & 38.43 & 50.34 & 40.50 & 18.54 & 55.67 \\
\hline n-Hexyl acetate & $1500^{2}$ & $\begin{array}{l}a \\
a\end{array}$ & 0.08 & 0.04 & 0.04 & 0.02 & 0.01 & $\begin{array}{l}70.04 \\
0.02\end{array}$ & 0.02 & 0.01 & 0.02 & 0.04 & 0.02 & 0.00 & 0.03 \\
\hline Ethyl lactate & $154,000^{2}$ & a & 0.01 & 0.10 & 0.01 & 0.03 & 0.09 & 0.06 & 0.03 & 0.08 & 0.06 & 0.01 & 0.02 & 0.01 & 0.02 \\
\hline Ethyl octanoate & $\begin{array}{c}104,000 \\
5^{1}\end{array}$ & $\begin{array}{l}a \\
a\end{array}$ & $\begin{array}{c}0.01 \\
197.92\end{array}$ & 118.20 & 148.07 & 178.75 & 73.00 & 153.72 & 127.54 & 160.28 & 111.16 & 130.38 & 112.48 & $\begin{array}{l}0.01 \\
87.09\end{array}$ & 129.58 \\
\hline Ethyl decanoate & $200^{1}$ & $\mathrm{a}$ & 1.11 & 0.42 & 0.60 & 0.60 & 0.30 & 0.60 & 0.59 & 1.05 & 0.45 & 0.70 & 0.48 & 0.26 & 0.62 \\
\hline$\beta$-Damascenone & $0.05^{1}$ & $\mathrm{~b}$ & 18.20 & 35.30 & 17.80 & 12.80 & 7.20 & 22.50 & 5.90 & 9.50 & 8.60 & 6.10 & 6.60 & 10.20 & 10.20 \\
\hline$\alpha$-Ionone & $2.6^{3}$ & $\mathrm{~b}$ & 0.31 & 0.30 & 0.29 & 0.30 & 0.29 & 0.29 & 0.29 & 0.29 & 0.30 & 0.29 & 0.29 & 0.29 & 0.29 \\
\hline 3-MH & $0.06^{1}$ & c & 1.97 & 0.05 & 0.68 & 1.92 & 6.07 & 0.00 & 2.48 & 0.60 & 0.47 & 3.30 & 0.17 & 4.97 & 4.83 \\
\hline Phenylethyl acetate & $250^{1}$ & $\mathrm{~d}$ & 1.19 & 0.33 & 0.33 & 0.10 & 0.19 & 0.54 & 0.54 & 0.18 & 0.38 & 0.36 & 0.35 & 0.11 & 0.25 \\
\hline Linalool & $15^{2}$ & $\mathrm{~d}$ & 0.33 & 0.08 & 0.11 & 0.06 & 0.00 & 0.02 & 0.00 & 0.05 & 0.00 & 0.04 & 0.03 & 0.00 & 0.02 \\
\hline Terpinen-4-ol & $100^{8}$ & $\mathrm{~d}$ & 0.01 & 0.01 & 0.01 & 0.01 & 0.01 & 0.01 & 0.01 & 0.01 & 0.01 & 0.01 & 0.00 & 0.00 & 0.01 \\
\hline$\alpha$-Terpineol & $250^{3}$ & $\mathrm{~d}$ & 0.02 & 0.01 & 0.01 & 0.01 & 0.01 & 0.01 & 0.01 & 0.01 & 0.01 & 0.01 & 0.00 & 0.01 & 0.01 \\
\hline$\beta$-Citronellol & $40^{2}$ & $\mathrm{~d}$ & 0.06 & 0.02 & 0.06 & 0.00 & 0.00 & 0.06 & 0.03 & 0.00 & 0.04 & 0.01 & 0.00 & 0.01 & 0.09 \\
\hline Geraniol & $30^{1}$ & $\mathrm{~d}$ & 0.07 & 0.04 & 0.09 & 0.02 & 0.03 & 0.01 & 0.00 & 0.04 & 0.02 & 0.01 & 0.02 & 0.05 & 0.00 \\
\hline 1,4-Cineole & $0.54^{13}$ & $\mathrm{e}$ & 0.52 & 0.75 & 0.61 & 1.96 & 1.65 & 1.15 & 0.71 & 1.50 & 1.15 & 0.63 & 1.08 & 1.33 & 0.99 \\
\hline 1,8 -Cineole & $1.1^{13}$ & e & 0.06 & 0.02 & 0.09 & 0.42 & 0.20 & 0.17 & 0.09 & 0.19 & 0.25 & 0.10 & 0.07 & 0.08 & 0.11 \\
\hline Methyl salicylate & $50^{11}$ & $\mathrm{e}$ & 0.38 & 3.84 & 0.53 & 1.00 & 0.28 & 0.38 & 0.15 & 0.35 & 0.53 & 1.13 & 0.23 & 0.75 & 0.42 \\
\hline 1-Butanol & $150,000^{2}$ & $\mathrm{f}$ & 0.00 & 0.00 & 0.00 & 0.00 & $\begin{array}{l}0.20 \\
0.00\end{array}$ & $\begin{array}{l}0.00 \\
0.00\end{array}$ & 0.00 & $\begin{array}{l}0.30 \\
0.00\end{array}$ & 0.00 & $\begin{array}{l}1.10 \\
0.00\end{array}$ & 0.00 & 0.00 & $\begin{array}{l}0.42 \\
0.00\end{array}$ \\
\hline Isoamyl alcohol & $30,000^{1}$ & $\mathrm{f}$ & 2.64 & 3.07 & 2.42 & 3.73 & 2.91 & 2.81 & 2.84 & 2.77 & 2.92 & 3.29 & 2.69 & 2.60 & 2.29 \\
\hline 1-Pentanol & $64,000^{12}$ & $\mathrm{f}$ & 0.00 & 0.00 & 0.00 & 0.00 & 0.00 & 0.00 & 0.00 & 0.00 & 0.00 & 0.00 & 0.00 & 0.00 & 0.00 \\
\hline 2-Phenylethanol & $14,000^{1}$ & $\mathrm{f}$ & 0.77 & 0.44 & 0.30 & 0.38 & 0.60 & 0.80 & 1.03 & 0.64 & 0.68 & 0.65 & 0.69 & 0.51 & 0.30 \\
\hline Methionol & $1000^{1}$ & $\mathrm{f}$ & 0.10 & 0.10 & 0.07 & 0.08 & 0.17 & 0.08 & 0.17 & 0.10 & 0.16 & 0.18 & 0.19 & 0.09 & 0.08 \\
\hline 3-Methylbutanoic acid & $33^{1}$ & $\mathrm{~g}$ & 7.47 & 6.22 & 4.94 & 3.76 & 5.68 & 5.36 & 9.25 & 5.85 & 7.13 & 6.84 & 8.41 & 7.85 & 4.92 \\
\hline Hexanoic acid & $420^{1}$ & $\begin{array}{l}5 \\
\mathrm{~g}\end{array}$ & 14.96 & 10.05 & 11.44 & 15.81 & 8.09 & 10.11 & 10.49 & 11.99 & 12.82 & $\begin{array}{l}0.74 \\
9.72\end{array}$ & $\begin{array}{l}0.11 \\
12.63\end{array}$ & 13.46 & 9.93 \\
\hline Octanoic acid & $500^{1}$ & $\begin{array}{l}\delta \\
\mathrm{g}\end{array}$ & 20.11 & 15.14 & 16.81 & 18.64 & 13.53 & 16.47 & 16.90 & 18.27 & 16.77 & 15.97 & 17.19 & 17.27 & 16.87 \\
\hline Vanillin & $60^{2}$ & $\stackrel{8}{h}$ & 0.00 & 0.18 & 0.11 & 0.00 & 0.06 & 0.17 & 0.31 & 0.04 & 0.08 & 0.08 & 0.06 & 0.11 & 0.07 \\
\hline Vanillyl alcohol & $5000^{6}$ & $\mathrm{~h}$ & 0.00 & 0.00 & 0.00 & 0.01 & 0.00 & 0.00 & 0.00 & 0.00 & 0.00 & 0.00 & 0.00 & 0.00 & 0.00 \\
\hline Methyl vanillate & $3000^{2}$ & $\mathrm{~h}$ & 0.00 & 0.00 & 0.00 & 0.00 & 0.00 & 0.00 & 0.00 & 0.00 & 0.00 & 0.00 & 0.00 & 0.00 & 0.00 \\
\hline Ethyl vanillate & $990^{2}$ & $\mathrm{~h}$ & 0.00 & 0.00 & 0.01 & 0.01 & 0.00 & 0.00 & 0.00 & 0.00 & 0.00 & 0.01 & 0.00 & 0.01 & 0.00 \\
\hline
\end{tabular}


Table 4. Cont.

\begin{tabular}{|c|c|c|c|c|c|c|c|c|c|c|c|c|c|c|c|}
\hline & & & L1 & L4 & L5 & L6 & V3 & V5 & V1 & V2 & V4 & V6 & V7 & L2 & L3 \\
\hline & $\begin{array}{c}\text { Odor } \\
\text { Threshold } \\
(\mu \mathrm{g} / \mathrm{L})\end{array}$ & $\begin{array}{l}\text { Aromatic } \\
\text { Series }\end{array}$ & $\begin{array}{c}\text { Cluster } \\
1\end{array}$ & $\begin{array}{c}\text { Cluster } \\
1\end{array}$ & $\begin{array}{c}\text { Cluster } \\
1\end{array}$ & $\begin{array}{c}\text { Cluster } \\
1\end{array}$ & $\underset{1}{\text { Cluster }}$ & $\underset{1}{\text { Cluster }}$ & $\underset{2}{\text { Cluster }}$ & $\underset{2}{\text { Cluster }}$ & $\underset{2}{\text { Cluster }}$ & $\begin{array}{c}\text { Cluster } \\
2\end{array}$ & $\underset{2}{\text { Cluster }}$ & $\underset{2}{\text { Cluster }}$ & $\begin{array}{c}\text { Cluster } \\
2\end{array}$ \\
\hline Benzaldehyde & $2000^{7}$ & $\mathrm{~h}$ & 0.01 & 0.03 & 0.02 & 0.01 & 0.01 & 0.01 & 0.01 & 0.01 & 0.01 & 0.01 & 0.01 & 0.01 & 0.01 \\
\hline Benzyl alcohol & $200,000^{7}$ & $\mathrm{~h}$ & 0.00 & 0.00 & 0.00 & 0.00 & 0.00 & 0.00 & 0.00 & 0.00 & 0.00 & 0.00 & 0.00 & 0.00 & 0.00 \\
\hline 4-Etilguaiacol & $33^{1}$ & $\mathrm{~h}$ & 0.10 & 0.10 & 0.09 & 0.09 & 3.13 & 0.00 & 0.56 & 0.00 & 0.00 & 0.09 & 0.10 & 0.10 & 0.09 \\
\hline 2,6-Dimethoxy phenol & $1850^{7}$ & $\mathrm{~h}$ & 0.00 & 0.00 & 0.00 & 0.00 & 0.00 & 0.00 & 0.00 & 0.00 & 0.00 & 0.00 & 0.00 & 0.00 & 0.00 \\
\hline 1-Hexanol & $8000^{1}$ & $\mathrm{i}$ & 0.09 & 0.09 & 0.08 & 0.14 & 0.12 & 0.09 & 0.12 & 0.12 & 0.14 & 0.13 & 0.13 & 0.13 & 0.09 \\
\hline trans-3-Hexenol & $1000^{5}$ & $\mathrm{i}$ & 0.03 & 0.05 & 0.06 & 0.07 & 0.08 & 0.05 & 0.05 & 0.08 & 0.10 & 0.05 & 0.05 & 0.07 & 0.11 \\
\hline cis-3-Hexenol & $400^{1}$ & $\mathrm{i}$ & 0.06 & 0.07 & 0.12 & 0.11 & 0.05 & 0.02 & 0.05 & 0.05 & 0.05 & 0.07 & 0.04 & 0.07 & 0.11 \\
\hline cis-2-Hexenol & $400^{4}$ & i & 0.03 & 0.03 & 0.02 & 0.02 & 0.02 & 0.02 & 0.02 & 0.03 & 0.02 & 0.02 & 0.02 & 0.02 & 0.03 \\
\hline DMS & $10^{1}$ & 1 & 0.17 & 0.11 & 0.10 & 0.20 & 0.17 & 0.04 & 0.02 & 0.31 & 0.14 & 0.07 & 0.12 & 0.17 & 0.15 \\
\hline DES & $18^{15}$ & 1 & 0.07 & 0.04 & 0.03 & 0.04 & 0.04 & 0.04 & 0.03 & 0.06 & 0.03 & 0.05 & 0.04 & 0.02 & 0.04 \\
\hline DMDS & $29^{14}$ & 1 & 0.00 & 0.00 & 0.00 & 0.00 & 0.00 & 0.00 & 0.00 & 0.00 & 0.00 & 0.00 & 0.00 & 0.00 & 0.00 \\
\hline DEDS & $4.3^{14}$ & 1 & 0.00 & 0.00 & 0.01 & 0.01 & 0.00 & 0.00 & 0.00 & 0.00 & 0.00 & 0.00 & 0.00 & 0.00 & 0.00 \\
\hline TPB & $0.04^{9}$ & $\mathrm{~m}$ & 1.13 & 2.38 & 1.38 & 0.00 & 1.75 & 2.88 & 1.38 & 2.75 & 1.75 & 1.13 & 1.75 & 2.25 & 2.13 \\
\hline TDN & $2^{10}$ & $\mathrm{~m}$ & 0.44 & 0.75 & 0.81 & 0.07 & 1.07 & 0.85 & 0.65 & 0.83 & 1.04 & 0.48 & 0.80 & 1.56 & 1.37 \\
\hline
\end{tabular}

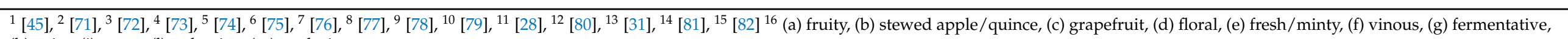

(h) spicy, (i) green, (l) reductive, (m) evolutive.

Table 5. Aromatic series values for each samples, and Mann-Whitney test between clusters. Significant values $(\alpha=0.1)$ are in bold.

\begin{tabular}{|c|c|c|c|c|c|c|c|c|c|c|c|c|c|c|}
\hline Sample: & L1 & L4 & L5 & L6 & V3 & V5 & L2 & L3 & V1 & $\mathrm{V} 2$ & V4 & V6 & V7 & Cluster Effect \\
\hline Cluster: & 1 & 1 & 1 & 1 & 1 & 1 & 2 & 2 & 2 & 2 & 2 & 2 & 2 & $p$-Value \\
\hline & 298 & 235 & 277 & 275 & 143 & 253 & 125 & 235 & 203 & 238 & 186 & 241 & 180 & 0.063 \\
\hline Stewed apple/quince & 18.20 & 35.30 & 17.80 & 12.80 & 7.20 & 22.50 & 10.20 & 10.20 & 5.90 & 9.50 & 8.60 & 6.10 & 6.60 & 0.015 \\
\hline Grapefruit & 1.97 & 0.05 & 0.68 & 1.92 & 6.07 & 0.00 & 4.97 & 4.83 & 2.48 & 0.60 & 0.47 & 3.30 & 0.17 & 0.475 \\
\hline Floral & 0.49 & 0.15 & 0.27 & 0.09 & 0.04 & 0.11 & 0.08 & 0.13 & 0.06 & 0.09 & 0.07 & 0.06 & 0.05 & 0.086 \\
\hline Fresh/Minty & 0.44 & 3.86 & 0.62 & 1.41 & 0.48 & 0.55 & 0.84 & 0.53 & 0.24 & 0.54 & 0.78 & 1.22 & 0.30 & 0.475 \\
\hline Vinous & 3.43 & 3.52 & 2.73 & 4.11 & 3.54 & 3.62 & 3.12 & 2.60 & 3.89 & 3.42 & 3.62 & 3.96 & 3.40 & 0.668 \\
\hline Fermentative & 42.5 & 31.4 & 33.2 & 38.2 & 27.3 & 31.9 & 38.6 & 31.7 & 36.6 & 36.1 & 36.7 & 32.5 & 38.2 & 0.391 \\
\hline Spicy & 0.11 & 0.32 & 0.24 & 0.12 & 3.22 & 0.19 & 0.23 & 0.18 & 0.89 & 0.06 & 0.09 & 0.20 & 0.18 & 0.391 \\
\hline Reductive & 0.47 & 0.33 & 0.40 & 0.47 & 0.35 & 0.20 & 0.34 & 0.34 & 0.22 & 0.54 & 0.28 & 0.30 & 0.39 & 0.475 \\
\hline Evolutive & 1.88 & 3.42 & 2.48 & 0.37 & 3.10 & 4.02 & 2.32 & 3.87 & 3.08 & 1.89 & 2.83 & 4.10 & 3.78 & 0.534 \\
\hline
\end{tabular}


The floral series included terpenes and it was significantly higher in Cluster 1 . However, the impact of this series on wine aroma appeared to be low as the score was below 1 in all wine samples. Nevertheless, it is reasonable that this aromatic series was not of primary importance for the characterization of the two aromatic types of wine (Clusters 1 and 2).

Finally, the contribution of the series green and reductive, appeared to be minor due to the low scores and in agreement with the fact that the panel did not use these descriptors to describe wine samples. The aromatic series 'evolutive', including TPB and TDN, did not show significant difference among clusters.

\section{Materials and Methods}

\subsection{Chemicals}

Octan-2-ol (97\%), 1-hexanol (99\%), cis-3-hexenol (98\%), trans-3-hexenol (97\%), vanillin (99\%), 2,6-dimethoxyphenol (99\%), linalool (97\%), terpinen-4-ol ( $\geq 95 \%)$, $\alpha$-terpineol (90\%), nerol $(\geq 97 \%)$, geraniol $(98 \%)$, linalool oxide $(\geq 97 \%), \beta$-citronellol $(95 \%), p$-cymene $(99 \%)$, terpinolene $(\geq 85 \%), \gamma$-terpinene $(\geq 97 \%)$, limonene $(97 \%), 1,8$-cineole $(99 \%), 1,4$-cineole $(\geq 98.5 \%)$, $\beta$-damascenone ( $\geq 98 \%)$, isoamyl alcohol (98\%), benzyl alcohol ( $\geq 99 \%)$, 2-phenylethanol $(\geq 99 \%)$, ethyl acetate (99\%), ethyl butanoate (99\%), ethyl 3-methyl butanoate ( $\geq 98 \%)$, isoamyl acetate $(\geq 95 \%)$, ethyl hexanoate $(\geq 95 \%)$, phenylethyl acetate $(99 \%), n$-hexyl acetate ( $\geq 98 \%)$, ethyl lactate $(\geq 98 \%)$, ethyl octanoate ( $\geq 98 \%)$, ethyl decanoate $(\geq 98 \%)$, hexanoic acid $(\geq 99 \%)$, octanoic acid ( $\geq 98 \%)$, $\alpha$-phellandrene (95\%), $p$-menthane-1,8-diol (97\%), 3 methylbutanoic acid (99\%), $\alpha$-ionone (90\%), 1-pentanol (99\%), 1-butanol ( $\geq 99 \%), 2$-butanol $(\geq 99 \%)$, ethyl guaiacol $(\geq 99 \%)$, vinyl guaiacol $(\geq 98 \%)$, methyl-vanillate $(99 \%)$, ethyl vanillate (99\%), were supplied by Sigma Aldrich (Milan, Italy). Dichloromethane $(\geq 99.8 \%)$ and methanol ( $\geq 99.8 \%$ ), were provided by Honeywell (Seelze, Germany). Sodium chloride ( $\geq 99.5 \%$ ) was supplied by Sigma Aldrich (Milan, Italy).

\subsection{Wine Samples}

Thirteen commercial wine samples (6 Lugana and 7 Verdicchio) were purchased for this study. Lugana wines were from 5 different wineries, while Verdicchio wine were all from different wineries. Samples were from 2016, 2017 and 2018 vintages (Table 6). Oenological parameters of the wines are given in Table 6. For each wine, two bottles were acquired and they were pooled before chemical analyses and sensory evaluation took place.

Table 6. Wine samples and base enological parameters.

\begin{tabular}{|c|c|c|c|c|c|c|c|c|c|c|c|c|}
\hline \multirow{2}{*}{$\begin{array}{c}\text { Code } \\
\text { L1 }\end{array}$} & \multirow{2}{*}{$\begin{array}{c}\text { Type } \\
\text { Lugana }\end{array}$} & \multirow{2}{*}{$\begin{array}{c}\text { Vintage } \\
2018\end{array}$} & \multicolumn{2}{|c|}{$\mathrm{pH}$} & \multicolumn{2}{|c|}{ Ethanol $(v / v \%)$} & \multicolumn{2}{|c|}{ Free $\mathrm{SO}_{2} \mathrm{mg} / \mathrm{L}$} & \multicolumn{2}{|c|}{ Total $\mathrm{SO}_{2} \mathrm{mg} / \mathrm{L}$} & \multicolumn{2}{|c|}{ Tartaric Acid g/L } \\
\hline & & & 3.45 & \pm 0.01 & 13 & \pm 0.5 & 16.3 & \pm 0.8 & 79.2 & \pm 3.2 & 2.65 & \pm 0.04 \\
\hline L2 & Lugana & 2016 & 2.98 & \pm 0.02 & 12.5 & \pm 0.5 & 9.0 & \pm 0.5 & 62.0 & \pm 1.9 & 2.85 & \pm 0.11 \\
\hline L3 & Lugana & 2017 & 3.1 & \pm 0.02 & 12.5 & \pm 0.5 & 14.1 & \pm 0.8 & 97.5 & \pm 0.9 & 2.77 & \pm 0.11 \\
\hline L4 & Lugana & 2017 & 3.16 & \pm 0.01 & 12.5 & \pm 0.5 & 10.3 & \pm 0.5 & 77.9 & \pm 2.3 & 3.34 & \pm 0.02 \\
\hline L5 & Lugana & 2018 & 3.27 & \pm 0.01 & 12.5 & \pm 0.5 & 19.8 & \pm 0.2 & 134.5 & \pm 2.4 & 2.91 & \pm 0.02 \\
\hline L6 & Lugana & 2016 & 3.18 & \pm 0.03 & 13.0 & \pm 0.5 & 11.8 & \pm 0.1 & 44.5 & \pm 2.2 & 1.96 & \pm 0.08 \\
\hline V1 & Verdicchio & 2017 & 3.27 & \pm 0.01 & 13.5 & \pm 0.5 & 17.4 & \pm 0.5 & 70.0 & \pm 0.7 & 3.04 & \pm 0.08 \\
\hline $\mathrm{V} 2$ & Verdicchio & 2016 & 3.4 & \pm 0.01 & 13.0 & \pm 0.5 & 10.1 & \pm 0.2 & 84.0 & \pm 1.4 & 2.26 & \pm 0.09 \\
\hline V3 & Verdicchio & 2017 & 3.22 & \pm 0.03 & 12.5 & \pm 0.5 & 20.7 & \pm 1.0 & 97.5 & \pm 1.9 & 3.28 & \pm 0.11 \\
\hline V4 & Verdicchio & 2017 & 3.27 & \pm 0.03 & 12.5 & \pm 0.5 & 20.7 & \pm 1.0 & 84.0 & \pm 0.8 & 3.55 & \pm 0.14 \\
\hline V5 & Verdicchio & 2017 & 3.07 & \pm 0.01 & 13.0 & \pm 0.5 & 8.5 & \pm 0.4 & 41.5 & \pm 2.5 & 3.09 & \pm 0.04 \\
\hline V6 & Verdicchio & 2018 & 3.38 & \pm 0.02 & 12.5 & \pm 0.5 & 23.1 & \pm 0.5 & 93.5 & \pm 1.7 & 3.85 & \pm 0.15 \\
\hline V7 & Verdicchio & 2017 & 3.25 & \pm 0.01 & 12.0 & \pm 0.5 & 22.95 & \pm 1.4 & 92 & \pm 0.5 & 3.55 & \pm 0.09 \\
\hline
\end{tabular}




\subsection{GC-MS Analysis}

\subsubsection{Volatile Sulfur Compounds Analysis}

The low boiling volatile sulfur compounds (VSC) dimethyl sulfide (DMS), diethyl sulfide (DES), Dimethyl disulfide (DMDS), ethyl thioacetate, diethyl disulfide (DEDS), dimethyl trisulfide (DMTS) were analyzed as described by Nguyen et al. (2010) [83] with minor modifications. Ten milliliters of wine were placed in $20 \mathrm{~mL}$ vials containing $3 \mathrm{~g}$ of $\mathrm{NaCl}$ and $100 \mu \mathrm{L}$ of internal standard (DMS-d6 at $2 \mathrm{mg} / \mathrm{L}$ ). The samples were incubated at $35^{\circ} \mathrm{C}$ for $5 \mathrm{~min}$, then the VSC were extracted by exposing a CAR-PDMS-DVB SPME fiber in the headspace for $30 \mathrm{~min}$. Desorption was performed in the injector at $270{ }^{\circ} \mathrm{C}$ for 7 min. Analysis was carried out using a HP 7890A (Agilent Technologies, Santa Clara, CA, USA) gas chromatographer coupled to a 5977B mass spectrometer. Injection was performed in splitless mode. Chromatographic separation was done using a DB-WAX capillary column $(30 \mathrm{~m} \times 0.25,0.25 \mu \mathrm{m}$ film thickness, Agilent Technologies). Helium was used as carrier gas at $1.0 \mathrm{~mL} / \mathrm{min}$ of constant flow rate. The oven temperature was programmed starting at $35{ }^{\circ} \mathrm{C}$ for $5 \mathrm{~min}$, then raised to $150{ }^{\circ} \mathrm{C}$ at $5{ }^{\circ} \mathrm{C} / \mathrm{min}$, and finally raised to $240^{\circ} \mathrm{C}$ at $10^{\circ} \mathrm{C} / \mathrm{min}$ and kept for $5 \mathrm{~min}$. Mass spectrometer operated in electron ionization (EI) at $70 \mathrm{eV}$ with ion source temperature at $250{ }^{\circ} \mathrm{C}$ and quadrupole temperature at $150{ }^{\circ} \mathrm{C}$. Acquisition was done in Selected Ion Monitoring (SIM), selected ion as well as method performance were reported in Table 7. Calibration curves were obtained using Chemstation software (Agilent Technologies, Inc.) by linear regression, plotting the response ratio (analyte peak area/internal standard peak area) against concentration ratio (analyte added concentration/internal standard concentration).

\subsubsection{3-Mercaptohexanol Analysis}

The polyfunctional thiol 3-mercaptohexanol (3-MH) was quantified using ethyl propiolate (ETP) derivatization followed by SPE extraction as described by Herbst-Johnstone et al. (2013) [84]. Internal standard, 1-hexanethiol (100 $\mu \mathrm{L}$ of a solution at concentration $0.25 \mathrm{mg} / \mathrm{L}$ in acetonitrile), was added to $50 \mathrm{~mL}$ of wine sample together with $1 \mathrm{~mL}$ of ethanolic solution of ETP $(100 \mathrm{mM})$. The $\mathrm{pH}$ was adjusted to $10.0 \pm 0.1$ by means of $10 \mathrm{~N}$ $\mathrm{NaOH}$ additions and stirred for $10 \mathrm{~min}$ at room temperature. Then the mixture was centrifugated at $6000 \mathrm{rpm}$ for $10 \mathrm{~min}$. The supernatant was then loaded on a BOND ELUT-ENV, SPE cartridge, containing $1 \mathrm{~g}$ of sorbent (Agilent Technlogies, USA), previously activated with $20 \mathrm{~mL}$ of methanol and equilibrated with $20 \mathrm{~mL}$ of water. The cartridge was then washed with $10 \mathrm{~mL}$ of water and the analytes were eluted with $10 \mathrm{~mL}$ of dichloromethane. The organic layer was dried with $\mathrm{Na}_{2} \mathrm{SO}_{4}$ and concentrated to about $30 \mu \mathrm{L}$ under a gentle nitrogen stream. Injection was performed in the injector at $250{ }^{\circ} \mathrm{C}$ in splitless mode. Analysis was carried out using a HP 7890A (Agilent Technologies) gas chromatographer coupled to a 5977B mass spectrometer. Chromatographic separation was done using a DBHeavyWAX capillary column ( $30 \mathrm{~m} \times 0.25,0.25 \mu \mathrm{m}$ film thickness, Agilent Technologies). Helium was used as carrier gas at $1.2 \mathrm{~mL} / \mathrm{min}$ of constant flow rate. The oven temperature was programmed starting at $70{ }^{\circ} \mathrm{C}$ for $5 \mathrm{~min}$, then raised to $162{ }^{\circ} \mathrm{C}$ at $10{ }^{\circ} \mathrm{C} / \mathrm{min}$, and finally raised to $280^{\circ} \mathrm{C}$ at $20^{\circ} \mathrm{C} / \mathrm{min}$ and kept for $20 \mathrm{~min}$. Mass spectrometer operated in electron ionization (EI) at $70 \mathrm{eV}$ with ion source temperature at $250{ }^{\circ} \mathrm{C}$ and quadrupole temperature at $150^{\circ} \mathrm{C}$. Acquisition was done in Selected Ion Monitoring (SIM), selected ion as well as method performance were reported in Table 7. Calibration curves were obtained using Chemstation software (Agilent Technologies, Inc.) by linear regression, plotting the response ratio (analyte peak area/internal standard peak area) against concentration ratio (analyte added concentration/internal standard concentration). 
Table 7. Retention indices, quantification ions of studied compounds.

\begin{tabular}{|c|c|c|c|c|c|c|c|}
\hline & Method $^{1}$ & LRI $^{1}$ & Identification $^{2}$ & $\begin{array}{c}\text { Quantitation } \\
\text { Ion } \mathbf{m} / \mathbf{z}\end{array}$ & $\begin{array}{l}\text { Qualifier } \\
\text { Ions m/z }\end{array}$ & $\begin{array}{c}\text { LOD } \\
(\mu \mathrm{g} / \mathrm{L})\end{array}$ & $\begin{array}{c}\text { LOQ } \\
(\mu \mathrm{g} / \mathrm{L})\end{array}$ \\
\hline 1-Butanol & $\mathrm{a}$ & 1159 & RS & 56 & 55 & 0.02 & 0.06 \\
\hline 2-Butanol & a & 1020 & RS & 59 & & 0.20 & 0.6 \\
\hline 1-Pentanol & a & 1256 & RS & 55 & $56,57,70$ & 0.04 & 0.11 \\
\hline Isoamyl alcohol & a & 1220 & RS & 57 & $55,56,70$ & 0.02 & 0.06 \\
\hline Methionol & a & 1710 & RS & 106 & $88,73,61$ & 2.1 & 6.3 \\
\hline Phenylethyl Alcohols & a & 1920 & RS & 91 & $65,92,122$ & 1.95 & 5.84 \\
\hline 1-Hexanol & a & 1316 & RS & 56 & 55,69 & 0.76 & 2.27 \\
\hline trans-3-Hexen-1-ol & a & 1379 & RS & 67 & $55,69,82$ & 0.40 & 1.21 \\
\hline cis-3-Hexen-1-ol & a & 1391 & RS & 68 & $55,69,83$ & 1.23 & 3.68 \\
\hline cis-2-Hexen-1-ol & a & 1431 & RS & 82 & 71,67 & 0.12 & 0.36 \\
\hline Isoamyl acetate & a & 1125 & RS & 70 & $55,60,87$ & 0.03 & 0.1 \\
\hline n-Hexyl acetate & a & 1271 & RS & 56 & $55,61,84$ & 0.03 & 0.1 \\
\hline 2-Phenethyl acetate & a & 1810 & RS & 104 & 91,78 & 0.10 & 0.30 \\
\hline $\begin{array}{l}\text { Ethyl 3-methyl } \\
\text { butanoate }\end{array}$ & a & 1069 & RS & 88 & $57,60,85$ & 0.30 & 0.9 \\
\hline Ethyl butanoate & a & 1032 & RS & 71 & 88 & 0.01 & 0.04 \\
\hline Ethyl hexanoate & a & 1240 & RS & 88 & 60,99 & 5.82 & 17.47 \\
\hline Ethyl octanoate & a & 1430 & RS & 88 & $57,100,127$ & 0.54 & 1.63 \\
\hline Ethyl decanoate & a & 1640 & RS & 88 & $71,101,155$ & 0.16 & 0.49 \\
\hline Ethyl lactate & a & 1340 & RS & 75 & 88,90 & 2.1 & 6.3 \\
\hline 3-Methylbutanoic acid & a & 1667 & RS & 60 & 87 & 0.17 & 0.52 \\
\hline Hexanoic acid & a & 1839 & RS & 60 & 73,87 & 0.15 & 0.46 \\
\hline Octanoic acid & a & 2071 & RS & 60 & $73,101,115$ & 0.00 & 0.01 \\
\hline cis-Linalooloxide & $\mathrm{b}$ & 1437 & RS & 59 & 111,94 & 0.02 & 0.07 \\
\hline trans-Linalooloxide & $\mathrm{b}$ & 1469 & RS & 59 & 111,94 & 0.02 & 0.07 \\
\hline Linalool & $b$ & 1547 & RS & 71 & 121,93 & 0.01 & 0.03 \\
\hline Geraniol & $b$ & 1860 & RS & 93 & $123,121,105$ & 0.02 & 0.07 \\
\hline$\beta$-Citronellol & $\mathrm{b}$ & 1771 & RS & 69 & $82,81,67$ & 0.07 & 0.21 \\
\hline$\alpha$-Terpineol & $\mathrm{b}$ & 1701 & $\mathrm{RS}$ & 136 & $121,93,59$ & 0.23 & 0.7 \\
\hline$\alpha$-Phellandrene & $\mathrm{b}$ & 1180 & RS & 93 & 136,91 & 0.001 & 0.003 \\
\hline Myrcene & $\mathrm{b}$ & 1160 & RS & 93 & 79,69 & 0.001 & 0.003 \\
\hline$p$-Cymene & $\mathrm{b}$ & 1271 & $\mathrm{RS}$ & 119 & 134,91 & 0.08 & 0.24 \\
\hline 3-Carene & $\mathrm{b}$ & 1130 & RS & 93 & 121,91 & 0.01 & 0.03 \\
\hline$\alpha$-Terpinen & $\mathrm{b}$ & 1190 & RS & 121 & 136,93 & 0.01 & 0.03 \\
\hline$\gamma$-Terpinen & $b$ & 1188 & RS & 121 & 93,126 & 0.03 & 0.1 \\
\hline Limonene & $\mathrm{b}$ & 1198 & RS & 136 & $139,125,111$ & 0.02 & 0.08 \\
\hline 1,4-Cineole & $\mathrm{b}$ & 1186 & RS & 154 & $139,111,108$ & 0.003 & 0.011 \\
\hline 1,8-Cineole & $b$ & 1217 & RS & 154 & $139,111,108$ & 0.003 & 0.011 \\
\hline p-Cymene & $b$ & 1271 & RS & 119 & 134,91 & 0.02 & 0.06 \\
\hline Terpinolene & $\mathrm{b}$ & 1283 & RS & 121 & 136,93 & 0.03 & 0.09 \\
\hline Terpinen-1-ol & $\mathrm{b}$ & 1581 & LRI MS & 136 & 121,81 & - & - \\
\hline Terpinen-4-ol & $\mathrm{b}$ & 1614 & RS & 71 & $111,93,86$ & 0.02 & 0.05 \\
\hline p-Menthane-1,8-diol & a & 2250 & RS & 96 & 88,139 & 0.03 & 0.09 \\
\hline Ho-trienol & $\mathrm{b}$ & 1585 & LRI MS & 82 & 67,71 & - & - \\
\hline Nerol & $\mathrm{b}$ & 1812 & RS & 93 & $121,84,69$ & 0.04 & 0.12 \\
\hline$\beta$-Damascenone & $\mathrm{b}$ & 1825 & RS & 69 & $190,121,105$ & 0.01 & 0.03 \\
\hline$\alpha$-Ionone & $\mathrm{b}$ & 1853 & RS & 121 & 136,192 & 0.02 & 0.06 \\
\hline$\alpha$-Ionol & $\mathrm{b}$ & 1925 & RS & 95 & 123,138 & 0.04 & 0.12 \\
\hline 3-Oxo- $\alpha$-ionol & a & 2555 & LRI MS & 108 & 152 & - & - \\
\hline $\begin{array}{l}\text { 3-Hydroxy- } \beta \text { - } \\
\text { damascone }\end{array}$ & a & 2532 & LRI MS & 175 & 208,193 & - & - \\
\hline Vitispirane 1 & $\mathrm{~b}$ & 1523 & LRI MS & 192 & 177,93 & - & - \\
\hline Vitispirane 2 & $\mathrm{~b}$ & 1529 & LRI MS & 192 & 177,93 & - & - \\
\hline TPB & $\mathrm{b}$ & 1828 & LRI MS & 172 & 157,142 & - & - \\
\hline $\mathrm{TDN}$ & $\mathrm{b}$ & 1745 & LRI MS & 157 & 172,142 & - & - \\
\hline
\end{tabular}


Table 7. Cont

\begin{tabular}{|c|c|c|c|c|c|c|c|}
\hline & Method $^{1}$ & LRI $^{1}$ & Identification $^{2}$ & $\begin{array}{l}\text { Quantitation } \\
\text { Ion } \mathrm{m} / \mathrm{z}\end{array}$ & $\begin{array}{l}\text { Qualifier } \\
\text { Ions } \mathrm{m} / \mathrm{z}\end{array}$ & $\begin{array}{c}\text { LOD } \\
(\mu \mathrm{g} / \mathrm{L})\end{array}$ & $\begin{array}{c}\mathrm{LOQ} \\
(\mu \mathrm{g} / \mathrm{L})\end{array}$ \\
\hline Nerolidol & $\mathrm{b}$ & 2024 & RS & 69 & $161,136,93$ & 0.015 & 0.05 \\
\hline Farnesol & $\mathrm{b}$ & 2300 & RS & 69 & $136,93,81$ & 0.03 & 0.1 \\
\hline Bisabolol & $\mathrm{b}$ & 2206 & RS & 204 & 119,109 & 0.03 & 0.1 \\
\hline Benzyl Alcohols & $\mathrm{a}$ & 1874 & RS & 106 & $105,77,51$ & 0.03 & 0.1 \\
\hline Vanillin & $\mathrm{a}$ & 2572 & RS & 151 & $81,152,109$ & 0.01 & 0.02 \\
\hline Vanillyl alcohol & $\mathrm{a}$ & 2781 & RS & 154 & 137,93 & 0.3 & 0.9 \\
\hline Furfural & $\mathrm{a}$ & 1461 & RS & 95 & 96,67 & 0.3 & 0.9 \\
\hline 4-Ethyl guaiacol & $\mathrm{a}$ & 1988 & RS & 137 & 122,152 & 0.03 & 0.09 \\
\hline 4-Ethyl phenol & $\mathrm{a}$ & 2212 & RS & 150 & 107,135 & 0.07 & 0.21 \\
\hline Ethyl vanillate & $\mathrm{a}$ & 2665 & RS & 151 & 168,196 & 2.36 & 7.09 \\
\hline Methyl salicylate & $\mathrm{a}$ & 1763 & RS & 120 & 152,92 & 0.45 & 1.35 \\
\hline Methyl vanillate & $\mathrm{a}$ & 2630 & RS & 151 & 123,182 & 0.97 & 2.91 \\
\hline Benzaldehyde & $\mathrm{a}$ & 1500 & RS & 106 & 105,77 & 0.87 & 2.61 \\
\hline 2,6-Dimethoxyphenol & $\mathrm{a}$ & 2270 & RS & 154 & $95,111,139$ & 0.01 & 0.03 \\
\hline 3-MH-ETP & C & 2670 & RS & 232 & 187,141 & 0.05 & 10 \\
\hline Carbon disulfide & $\mathrm{d}$ & 760 & RS & 76 & 78 & 0.01 & 0.03 \\
\hline DMS & $\mathrm{d}$ & 770 & RS & 62 & 61,47 & 0.02 & 0.06 \\
\hline DES & $\mathrm{d}$ & 910 & RS & 90 & $75,61,62$ & 0.03 & 0.09 \\
\hline DMDS & $\mathrm{d}$ & 1075 & RS & 94 & 79,64 & 0.09 & 0.27 \\
\hline Ethyl thioacetate & $\mathrm{d}$ & 1090 & $\mathrm{RS}$ & 104 & 62,60 & 0.03 & 0.09 \\
\hline DEDS & $\mathrm{d}$ & 1180 & RS & 122 & 94,66 & 0.06 & 0.18 \\
\hline DMTS & $\mathrm{d}$ & 1375 & RS & 126 & 111,79 & 0.07 & 0.21 \\
\hline
\end{tabular}

${ }^{1}$ Method: a (SPE for major compounds), b (SPME method for minor compounds), c (ETP derivatization followed by SPE extraction), d (SPME method for volatile sulfur compounds) ${ }^{2}$ Linear Retention Index (LRI) were determined on DB-WAX polar column, as described by van Den Dool and Kratz (1963) [85]. RS identified using reference standard; LRI MS tentatively identified by comparing the Linear Retention Index and mass spectra with those of literature.

3.3.3. Determination of Major Esters, Alcohols, Acids, Benzenoids, Terpenes and Glycosidically-Bound Compounds

Quantitatively major volatile compounds, mostly of fermentative origin, have been analyzed as described by Slaghenaufi et al. (2019) [11] with minor modifications. Fifty milliliters of sample were added with $20 \mu \mathrm{L}$ of internal standard solution (2-octanol at $42 \mathrm{mg} / \mathrm{L}$ in ethanol) and diluted with $50 \mathrm{~mL}$ of distilled water. The solution was then loaded on a BOND ELUT-ENV, SPE cartridge, containing $1 \mathrm{~g}$ of sorbent (Agilent Technlogies. USA), previously activated with $20 \mathrm{~mL}$ of methanol and equilibrated with $20 \mathrm{~mL}$ of water. The cartridge was then washed with $15 \mathrm{~mL}$ of water. Free volatile compounds were eluted with $10 \mathrm{~mL}$ of dichloromethane, and then concentrated under gentle nitrogen stream to $200 \mu \mathrm{L}$ prior to GC injection. Bound compounds were recovered with $20 \mathrm{~mL}$ of methanol. Methanol was then evaporated under vacuum. Bound compounds were then dissolved in $5 \mathrm{~mL}$ of citrate buffer ( $\mathrm{pH}$ 5). were added to dissolve bound compounds to that $200 \mu \mathrm{L}$ of an enzyme preparation AR2000 (DSM, Brussels, Belgium, prepared at $70 \mathrm{mg} / \mathrm{mL}$ in citrate buffer) were added and incubated at $37^{\circ} \mathrm{C}$ for $24 \mathrm{~h}$ under shaking (150 rpm).

A calibration curve was prepared for each analyte using seven concentration points and three replicate solutions per point in model wine $(12 \% \mathrm{v} / \mathrm{v}$ ethanol, $3.5 \mathrm{~g} / \mathrm{L}$ tartaric acid, $\mathrm{pH}$ 3.5). A total of $20 \mu \mathrm{L}$ of internal standards 2 -octanol $(42 \mathrm{mg} / \mathrm{L}$ in ethanol), was added to the solution. SPE extraction and GC-MS analysis were performed as described above for the samples. Calibration curves were obtained using Chemstation software (Agilent Technologies, Inc.) by linear regression, plotting the response ratio (analyte peak area/internal standard peak area) against concentration ratio (analyte added concentration / internal standard concentration). Method characteristics are reported in Table 7 (Supplementary Materials Figure S1). The 3-oxo- $\alpha$-ionol analysis was semi-quantitative and they were expressed as $\mu \mathrm{g} / \mathrm{L}$ of 2-octanol equivalent (internal standard) as for this compound no commercial standard was available. 


\subsubsection{Minor Terpenes, Norisoprenoids, Benzenoids}

Quantitatively minor terpenes have been analyzed by SPME-GC-MS as described by Slaghenaufi and Ugliano (2018) [33]. Five milliliter of wine added with $5 \mu \mathrm{L}$ of internal standard solution (octen-2-ol at $420 \mathrm{mg} / \mathrm{L}$ in ethanol) was placed into a $20 \mathrm{~mL}$ vial, together with $5 \mathrm{~mL}$ of $\mathrm{mQ}$ water $(18.2 \mathrm{M} \Omega-\mathrm{cm})$ and $3 \mathrm{~g}$ of $\mathrm{NaCl}$. Sample was equilibrated for $1 \mathrm{~min}$ at $40{ }^{\circ} \mathrm{C}$. Subsequently SPME extraction was performed using a 50/30 $\mu$ m divinylbenzenecarboxen-polydimethylsiloxane (DVB/CAR/PDMS) fiber (Supelco, Bellafonte, PA, USA) exposed to sample headspace for $60 \mathrm{~min}$ at $40{ }^{\circ} \mathrm{C}$. The fiber was then desorbed into the injector port of a HP 7890A (Agilent Technologies, USA) gas chromatographer coupled to a 5977B mass spectrometer. Injection was performed at $250{ }^{\circ} \mathrm{C}$ for $5 \mathrm{~min}$ in splitless mode. Chromatographic separation was done using a DB-WAX capillary column $(30 \mathrm{~m} \times 0.25$, $0.25 \mu \mathrm{m}$ film thickness, Agilent Technologies, USA). Helium was used as carrier gas at $1.2 \mathrm{~mL} / \mathrm{min}$ of constant flow rate. The temperature of the GC oven was initially kept at $40{ }^{\circ} \mathrm{C}$ for $3 \mathrm{~min}$, and then programmed to raise at $230{ }^{\circ} \mathrm{C}$ at $4{ }^{\circ} \mathrm{C} / \mathrm{min}$, maintained for $20 \mathrm{~min}$. Mass spectrometer operated in electron ionization (EI) at $70 \mathrm{eV}$ with ion source temperature at $250{ }^{\circ} \mathrm{C}$ and quadrupole temperature at $150{ }^{\circ} \mathrm{C}$. Acquisition was done in Selected Ion Monitoring (SIM). Quantification was performed using calibration curve obtained by standards addition at 7 different concentration levels in white wine. A total of $5 \mu \mathrm{L}$ of internal standards 2-octanol ( $420 \mathrm{mg} / \mathrm{L}$ in Ethanol), $5 \mathrm{~mL}$ of water and $3 \mathrm{~g}$ of NaCl were added to $5 \mathrm{~mL}$ of standard solutions. GC-MS analysis was performed as described above for the samples. Linear term for calibration curves were obtained using Chemstation software (Agilent Technologies, Inc.) by linear regression, plotting the response ratio (analyte peak area/internal standard peak area) against concentration ratio (analyte added concentration/internal standard concentration). The analysis of vitispirane, terpinen-1-ol, TPB, TDN, ho-trienol was semiquantitative as no standards was available. Results for these molecules were expressed as $\mu \mathrm{g} / \mathrm{L}$ of 2-octanol equivalent (internal standard) (Table 7).

\subsection{Sorting Task}

A sorting task was used to identify if Verdicchio and Lugana samples were aromatically different. The sorting task was done by an orthonasal evaluation following the method described by Alegre et al. (2017) [61]. The panelists were asked to sort the wines into groups based on aroma similarities, the number of possible groups was not defined. The panel consisted of 16 judges, members of the enology laboratory or enology bachelor students of the University of Verona. The ages of the panelists ranged from 21 to 46 years, and females were $31 \%$ of the panel. Twenty milliliters of wine samples were served at room temperature into ISO glasses (ISO 3591:1977) coded with random three-digit numbers. Subsequently, it was asked to indicate two descriptors for each group. Descriptors were chosen among fruity, floral, fresh/minty, green, dry herbs, spicy and fermentative. The similarity matrices of the individual judges were added together to obtain a single global matrix. The global matrix was used to performed hierarchical cluster analysis (HCA) with Ward criteria. To analyze the descriptors, the quotation frequencies of the various descriptors were calculated for each wine. Only terms cited by at least $30 \%$ of the panel were considered in the description of the groups [61].

\subsection{Statistical Analyses}

Statistical analysis was performed using XLSTAT 2017 (Addinsoft SARL, Paris, France). Shapiro-Wilk test was used to verify the normal distribution of the data. Due to the small number of samples and their non-normal distribution the Mann-Whitney test was used to determine statistical differences between Lugana and Verdicchio and between the sorting task clusters with a significant level of $\alpha=0.1$. PLS-DA was used to identify compounds characterizing Lugana and Verdiccho wines, using MetaboAnalyst v. 5.0 (http: / / www.metaboanalyst.ca, accessed on 16 March 2021), created at the University of Alberta, Edmonton, AB, Canada [86]. Prior to statistical analysis data were autoscaled. 


\section{Conclusions}

The present research investigated the existence of two distinct sensory spaces between two Italian white wines Lugana and Verdicchio, made using the same cultivar Trebbiano di Soave or Verdicchio, but grown in two very different areas. Lugana is produced in the lower Lake Garda and Verdicchio in the Marche region. Despite the limited sampling of 13 wines to our knowledge, this was the first time that these two wines were compared regarding their odor and volatile compound profiles.

Verdicchio and Lugana were similar in the majority of compounds analyzed, showing a general volatile compound profile common to the two wines and probably characteristic of the variety. However, a group of volatile compounds and precursors (13 and 6 respectively) were able to clearly discriminate the two wines. These markers belonged to different chemical classes (terpenes, higher alcohols, benzenoids, norisoprenoids, $\mathrm{C}_{6}$ compounds, confirming the existence of chemical signatures associated with the area of production of the wines. Sensory assessment showed that samples were divided into two clusters, highlighting the existence of two types of wine. The first cluster was described as fruity, fresh/minty, mainly formed by the majority of Lugana wines, while the other described with fermentative and spicy notes, with a prevalence of Verdicchio wines. Looking at the chemical bases of the two clusters, it could be shown that the main drivers of diversity for the two clusters were the fatty acid ethyl esters ethyl hexanoate and ethyl octanoate, isoamyl acetate and the norisoprenoid $\beta$-damascenone, which appear to well explain the differences in fruitiness. Although the clusters were also distinguished by attributes such as minty and spicy, we were not able to correlate these to any specific chemical feature of the wines analyzed. The limitations of the sensory approach used, namely the sorting task, could be partly responsible for this, as the employed method did not provide quantitative data which can be used to build regression models. Also, applications of even more articulated integrated analytical approaches could lead to identification of additional odorant compounds that could contribute to Verdicchio and Lugana aroma. Finally, we have evidenced the presence, in Lugana and Verdicchio, of a number of cyclic terpenes having minty and balsamic aromas, in particular cineoles. Odor synergies of these compounds and the other balsamic odorant methyl salicylate should be further investigated in relation to the minty character of some of the wines analyzed.

This work contributes to characterize the aroma of Lugana and Verdicchio wines by highlighting their common points and differences. The results obtained highlighted the existence of chemical and sensory differences, highlighting the importance of the geographical origin of the wines as a driver of uniqueness. They will also help winemakers to manage the aroma expression of their wines to enhance the expression of the characteristics mostly associated with the different geographical origin.

Supplementary Materials: The following are available, Figure S1: Total Ions Chromatogram (TIC) of V1 (Verdicchio) and L1 (Lugana) samples.

Author Contributions: M.U. conceived and designed the experiments. D.S., G.L., J.S.S. and F.F. performed all the experimental work and data analysis, D.S. and M.U. interpreted the data and drafted the manuscript. All authors have read and agreed to the published version of the manuscript.

Funding: This research received no external funding.

Institutional Review Board Statement: Not applicable.

Informed Consent Statement: Not applicable.

Data Availability Statement: The data presented in this study are available on request from the corresponding author.

Conflicts of Interest: The authors declare no conflict of interest.

Sample Availability: Samples of the compounds are available from the authors. 


\section{References}

1. Lubinga, M.H.; Ngqangweni, S.; Van der Walt, S.; Potelwa, Y.; Nyhodo, B.; Phaleng, L.; Ntshangase, T. Geographical indications in the wine industry: Does it matter for South Africa? Int. J. Wine Bus. Res. 2020, in press. [CrossRef]

2. Cross, R.; Plantinga, A.J.; Stavins, R.N. What is the value of terroir? Am. Econ. Rev. 2011, 101, 152-156. [CrossRef]

3. Van Leeuwen, C.; Barbe, J.-C.; Darriet, P.; Geffroy, O.; Gomès, E.; Guillaumie, S.; Helwi, P.; Laboyrie, J.; Lytra, G.; Le Menn, N.; et al. Recent advancements in understanding the terroir effect on aromas in grapes and wines. OENO One 2020, 54, 985-1006.

4. Roullier-Gall, C.; Boutegrabet, L.; Gougeon, R.D.; Schmitt-Kopplin, P. A grape and wine chemodiversity comparison of different appellations in Burgundy: Vintage vs terroir effects. Food Chem. 2014, 152, 100-107. [CrossRef]

5. Roullier-Gall, C.; Lucio, M.; Noret, L.; Schmitt-Kopplin, P.; Gougeon, R.D. How subtle is the "terroir" effect? Chemistry-related signatures of two "Climats de Bourgogne". PLoS ONE 2014, 9, e97615. [CrossRef]

6. Bramley, R.G.V.; Siebert, T.E.; Herderich, M.J.; Krstic, M.P. Patterns of within-vineyard spatial variation in the 'pepper' compound rotundone are temporally stable from year to year. Aust. J. Grape Wine Res. 2017, 23, 42-47. [CrossRef]

7. Sabon, I.; De Revel, G.; Kotseridis, Y.; Bertrand, A. Determination of volatile compounds in Grenache wines in relation with different terroirs in the Rhone Valley. J. Agric. Food Chem. 2002, 50, 6341-6345. [CrossRef]

8. Forcen, M.; Berna, A.; Mulet, A. Using aroma components to characterize Majorcan varietal red wines and musts. LWT 1993, 26, 54-58. [CrossRef]

9. Heymann, H.; Robinson, A.L.; Buscema, F.; Stoumen, M.E.; King, E.S.; Hopfer, H.; Boulton, R.B.; Ebeler, S.E. Effect of region on the volatile composition and sensory profiles of Malbec and cabernet sauvignon wines. ACS Symp. Ser. 2015, 1203, 109-122.

10. Robinson, A.L.; Boss, P.K.; Heymann, H.; Solomon, P.S.; Trengove, R.D. Influence of yeast strain, canopy management, and site on the volatile composition and sensory attributes of cabernet sauvignon wines from Western Australia. J. Agric. Food Chem. 2011, 59, 3273-3284. [CrossRef]

11. Slaghenaufi, D.; Guardini, S.; Tedeschi, R.; Ugliano, M. Volatile terpenoids, norisoprenoids and benzenoids as markers of fine scale vineyard segmentation for Corvina grapes and wines. Food Res. Int. 2019, 125, 1-10. [CrossRef]

12. Ji, T.; Dami, I. Characterization of free flavor compounds in Traminette grape and their relationship to vineyard training system and location. J. Food Sci. 2008, 73, 262-267. [CrossRef]

13. Celik, Z.D.; Karaoğlan, S.Y.; Darıcı, M.; Kelebek, H.; Isçi, B.; Kaçar, E. Effects of terroir on the terpene compounds of Muscat of Bornova Native white grape variety grown in Turkey. BIO Web Conf. 2015, 01004. [CrossRef]

14. Villanova, M.; Zamuz, S.; Vilariño, F.; Sieiro, C. Effect of terroir on the volatiles of Vitis vinifera cv. Albariño. J. Sci. Food Agric. 2007, 87, 1252-1256. [CrossRef]

15. Wen, Y.; Zhong, G.; Gao, Y.; Lan, Y.; Duan, C.; Pan, Q. Using the combined analysis of transcripts and metabolites to propose key genes for differential terpene accumulation across two regions. BMC Plant Biol. 2015, 15, 1-22. [CrossRef]

16. Robinson, A.; Boss, P.; Solomon, P.; Trengove, R.; Heymann, H.; Ebeler, S. Origins of Grape and Wine Aroma. Part 1. Chemical Components and Viticultural Impacts. Am. J. Enol. Vitic. 2014, 65, 1-24. [CrossRef]

17. Oliveira, J.; Faria, M.; Sá, F.; Barros, F.; Araújo, I. C6-alcohols as varietal markers for assessment of wine origin. Anal. Chim. Acta 2006, 563, 300-309. [CrossRef]

18. Úbeda, C.; Del Barrio-Galán, R.; Peña-Neira, Á.; Medel-Marabolí, M.; Durán-Guerrero, E. Location effects on the aromatic composition of monovarietal cv. Carignan wines. Am. J. Enol. Vitic. 2017, 68, 390-399. [CrossRef]

19. Keyzers, R.; Boss, P. Changes in the Volatile Compound Production of Fermentations Made from Musts with Increasing Grape Content. J. Agric. Food Chem. 2010, 58, 1153-1164. [CrossRef]

20. Luzzini, G.; Slaghenaufi, D.; Pasetto, F.; Ugliano, M. Influence of grape composition and origin, yeast strain and spontaneous fermentation on aroma profile of Corvina and Corvinone wines. LWT 2021, 143, 111120. [CrossRef]

21. Schueuermann, C.; Khakimov, B.; Engelsen, S.B.; Bremer, P.; Silcock, P. GC-MS Metabolite Profiling of Extreme Southern Pinot noir Wines: Effects of Vintage, Barrel Maturation, and Fermentation Dominate over Vineyard Site and Clone Selection. J. Agric. Food Chem. 2016, 64, 2342-2351. [CrossRef]

22. Zhang, X.; Kontoudakis, N.; Šuklje, K.; Antalick, G.; Blackman, J.W.; Rutledge, D.N.; Schmidtke, L.M.; Clark, A.C. Changes in Red Wine Composition during Bottle Aging: Impacts of Grape Variety, Vineyard Location, Maturity, and Oxygen Availability during Aging. J. Agric. Food Chem. 2020, 68, 13331-13343. [CrossRef]

23. Bokulich, N.A.; Collins, T.S.; Masarweh, C.; Allen, G.; Heymann, H.; Ebeler, S.E.; Mills, D.A. Associations among wine grape microbiome, metabolome, and fermentation behavior suggest microbial contribution to regional wine characteristics. $m B i o$ 2016, 7, 3. [CrossRef]

24. Bramley, R.G.V. Vineyard variability and terroir-Making sense of a sense of place. In Proceedings 16th Australian Wine Industry Technical Conference. Glen Osmond: Australian Wine Industry Technical Conference; Beames, K., Robinson, E., Dry, P., Johnson, D., Eds.; The Australian Wine Industry Technical Conference Inc.: Urrbrae, Adelaide, Australia, 2016; pp. 45-51.

25. Ghidoni, F.; Emanuelli, F.; Moreira Maia, F.; Imazio, S.; Scienza, A.; Grando, M.S. Variazioni del genotipo molecolare in Verdicchio, Trebbiano di Soave e Trebbiano di Lugana. Italus Hortus 2010, 17, 373-380.

26. Vantini, F.; Tacconi, G.; Gastaldelli, M.; Govoni, C.; Tosi, E.; Malacrinò, P.; Bassi, R.; Cattivelli, L. Biodiversity of grapevines (Vitis vinifera L.) grown in the province of Verona. Vitis 2003, 42, 35-38.

27. Costacurta, A.; Calò, A.; Crespan, M. The varietal identification and characterisation work of the 'Istituto Sperimentale per la Viticoltura' in the past fifteen years. Acta Hortic. 2003, 603, 261-273. [CrossRef] 
28. Carlin, S.; Vrhovsek, U.; Lonardi, A.; Landi, L.; Mattivi, F. Aromatic complexity in Verdicchio wines. A case study. OENO One 2019, 53. [CrossRef]

29. Fracassetti, D.; Camoni, D.; Montresor, L.; Bodon, R.; Limbo, S. Chemical characterization and volatile profile of trebbiano di lugana wine: A case study. Foods 2020, 9, 956. [CrossRef] [PubMed]

30. Mattivi, F.; Fedrizzi, B.; Zenato, A.; Tiefenthaler, P.; Tempesta, S.; Perenzoni, D.; Cantarella, P.; Simeoni, F.; Vrhovsek, U. Development of reliable analytical tools for evaluating the influence of reductive winemaking on the quality of Lugana wines. Anal. Chim. Acta 2012, 732, 194-202. [CrossRef] [PubMed]

31. Antalick, G.; Tempère, S.; Suklje, K.; Blackman, J.; Deloire, A.; De Revel, G.; Schmidtke, L.M. Investigation and sensory characterization of 1,4-cineole: A potential aromatic marker of australian cabernet sauvignon wine. J. Agric. Food Chem. 2015, 63, 9103-9111. [CrossRef] [PubMed]

32. Fariña, L.; Boido, E.; Carrau, F.; Versini, G.; Dellacassa, E. Terpene compounds as possible precursors of 1,8-cineole in red grapes and wines. J. Agric. Food Chem. 2005, 53, 1633-1636. [CrossRef]

33. Slaghenaufi, D.; Ugliano, M. Norisoprenoids, sesquiterpenes and terpenoids content of Valpolicella wines during aging: Investigating aroma potential in relationship to evolution of tobacco and balsamic aroma in aged wine. Front. Chem. 2018, 6, 66. [CrossRef]

34. Ribéreau-Gayon, P.; Boidron, J.N.; Terrier, A. Aroma of Muscat Grape Varieties. J. Agric. Food Chem. 1975, $23,1042-1047$. [CrossRef]

35. Laule, O.; Fürholz, A.; Chang, H.-S.; Zhu, T.; Wang, X.; Heifetz, P.B.; Gruissem, W.; Lange, M. Crosstalk between cytosolic and plastidial pathways of isoprenoid biosynthesis in Arabidopsis thaliana. Proc. Natl. Acad. Sci. USA 2003, 100, 6866-6871. [CrossRef]

36. Ugliano, M.; Bartowsky, E.J.; McCarthy, J.; Moio, L.; Henschke, P.A. Hydrolysis and transformation of grape glycosidically bound volatile compounds during fermentation with three Saccharomyces yeast strains. J. Agric. Food Chem. 2006, 54, 6322-6331. [CrossRef]

37. Belancic, A.; Agosin, E.; Ibacache, A.; Bordeu, E.; Baumes, R.; Razungles, A.; Bayonove, C. Influence of sun exposure on the aromatic composition of chilean Muscat grape cultivars Moscatel de Alejandria and Moscatel rosada. Am. J. Enol. Vitic 1997, 48, 181-186.

38. Duchêne, E.C.; Schneider, C. Grapevine and climatic changes: A glance at the situation in Alsace. Agron. Sustain. Dev. 2005, 25, 93-99. [CrossRef]

39. Carlin, S.; Vrhovsek, U.; Franceschi, P.; Lotti, C.; Bontempo, L.; Camin, F.; Toubiana, D.; Zottele, F.; Toller, G.; Fait, A.; et al. Regional features of northern Italian sparkling wines, identified using solid-phase micro extraction and comprehensive two-dimensional gas chromatography coupled with time-of-flight mass spectrometry. Food Chem. 2016, 208, 68-80. [CrossRef]

40. Sefton, M.A.; Skouroumounis, G.K.; Elsey, G.M.; Taylor, D.K. Occurrence, sensory impact, formation, and fate of damascenone in grapes, wines, and other foods and beverages. J. Agric. Food Chem. 2011, 59, 9717-9746. [CrossRef]

41. Lloyd, N.D.R.; Capone, D.L.; Ugliano, M.; Taylor, D.K.; Skouroumounis, G.K.; Sefton, M.A.; Elsey, G.M. Formation of damascenone under both commercial and model fermentation conditions. J. Agric. Food Chem. 2011, 59, 1338-1343. [CrossRef]

42. Lukic, I.; Radeka, S.; Grozaj, N.; Staver, M.; Persuric, D. Changes in physico-chemical and volatile aroma compound composition of Gewurztraminer wine as a result of late and ice harvest. Food Chem. 2016, 196, 1048-1057. [CrossRef]

43. Slaghenaufi, D.; Boscaini, A.; Prandi, A.; Dal Cin, A.; Zandonà, V.; Luzzini, G.; Ugliano, M. Influence of Different Modalities of Grape Withering on Volatile Compounds of Young and Aged Corvina Wines. Molecules 2020, 25, 2141. [CrossRef]

44. Gerdes, S.M.; Winterhalter, P.; Ebeler, S.E. Effect of sunlight exposure on norisoprenoid formation in White Riesling grapes. ACS Symp. Ser. 2002, 802, 262-272.

45. Francis, L.; Newton, J. Determining wine aroma from compositional data. Aust. J. Grape Wine Res. 2005, 11, 114-126. [CrossRef]

46. Slaghenaufi, D.; Marchand-Marion, S.; Richard, T.; Waffo-Teguo, P.; Bisson, J.; Monti, J.-P.; Merillon, J.-M.; De Revel, G. Centrifugal partition chromatography applied to the isolation of oak wood aroma precursors. Food Chem. 2013, 141, 2238-2245. [CrossRef]

47. Slaghenaufi, D.; Perello, M.-C.; Marchand-Marion, S.; De Revel, G. Quantitative solid phase microextraction-gas chromatography mass spectrometry analysis of five megastigmatrienone isomers in aged wine. Anal. Chim. Acta 2014, 813, 63-69. [CrossRef] [PubMed]

48. Slaghenaufi, D.; Perello, M.-C.; Marchand-Marion, S.; De Revel, G. Quantification of megastigmatrienone, a potential contributor to tobacco aroma in spirits. Food Chem. 2016, 203, 41-48. [CrossRef]

49. Carlin, S.; Masuero, D.; Guella, G.; Vrhovsek, U.; Mattivi, F. Methyl salicylate glycosides in some Italian varietal wines. Molecules 2019, 24, 3260. [CrossRef]

50. Mansfield, A.K.; Schirle-Keller, J.-P.; Reineccius, G.A. Identification of Odor-Impact Compounds in Red Table Wines Produced from Frontenac Grapes. Am. J. Enol. Vitic 2011, 62, 169-175. [CrossRef]

51. Guth, H. Identification of character impact odorants of different white wine varieties. J. Agric. Food Chem. 1997, 45, 3027-3032. [CrossRef]

52. Ugliano, M. Enzymes in winemaking. In Wine Chemistry and Biochemistry; Moreno-Arribas, M.V., Polo, M.C., Eds.; Springer: New York, NY, USA, 2009; pp. 103-126.

53. Versini, G.; Orriols, I.; Dalla Serra, A. Aroma components of Galician Albariño, Loureira and Godello wines. Vitis 1994, 33, 165-170. 
54. Nicolini, G.; Versini, G.; Dalla Serra, A.; Seppi, A.; Falcetti, M. Peculiarities in the aroma compounds of Muller-Thurgau wines from different grape growing areas. In Proceedings of the C.R. $5^{\circ}$ Symp. Int. CEnology “CEno1ogie 95”, Bordeaux, France, 15-17 June 1995; Lonvaud-Funel, A., Ed.; Tee \& Doe Pub: Paris, France, 1996; pp. 539-543.

55. Kalua, C.A.; Boss, P.K. Evolution of Volatile Compounds during the Development of Cabernet Sauvignon Grapes (Vitis vinifera L.). J. Agric. Food Chem. 2009, 57, 3818-3830. [CrossRef] [PubMed]

56. Nicolini, G.; Versini, G.; Amadei, E.; Marchio, M. 3-hexen-1-ol isomers in Muller-Thurgau wines: A “varietal’. characteristic affected by must sulfiting time. Vitis 1996, 35, 147-148.

57. Ramey, D.; Bertrans, A.; Ough, C.S.; Singleton, V.L.; Sanders, E. Effects of skin contact temperature on Chardonnay must and wine composition. Am. J. Enol. Vitic. 1986, 37, 99-106.

58. Tominaga, T.; BaltenweckGuyot, R.; Des Gachons, C.P.; Dubourdieu, D. Contribution of volatile thiols to the aromas of white wines made from several Vitis Vinifera grape varieties. Am. J. Enol. Vitic. 2000, 51, 178-181.

59. Slaghenaufi, D.; Tonidandel, L.; Moser, S.; Román Villegas, T.; Larcher, R. Rapid Analysis of 27 Volatile Sulfur Compounds in Wine by Headspace Solid-Phase Microextraction Gas Chromatography Tandem Mass Spectrometry. Food Anal. Methods 2017, 10, 3706-3715. [CrossRef]

60. Alegre, Y.; Sáenz-Navajas, M.-P.; Hernández-Orte, P.; Ferreira, V. Sensory, olfactometric and chemical characterization of the aroma potential of Garnacha and Tempranillo winemaking grapes. Food Chem. 2020, 331, 127207. [CrossRef]

61. Alegre, Y.; Sáenz-Navajas, M.-P.; Ferreira, V.; García, D.; Razquin, I.; Hernández-Orte, P. Rapid strategies for the determination of sensory and chemical differences between a wealth of similar wines. Eur. Food Res. Technol. 2017, 243, 1295-1309. [CrossRef]

62. Sáenz-Navajas, M.-P.; Alegre, Y.; De-la-Fuente, A.; Ferreira, V.; García, D.; Eizaguirre, S.; Razquin, I.; Hernández-Orte, P. Rapid sensory-directed methodology for the selection of high-quality aroma wines. J. Sci. Food Agric. 2016, 96, 4250-4262. [CrossRef]

63. Candelon, M.; Ballester, J.; Uscidda, N.; Blanquet, J.; Le Fur, Y. Sensory methodology developed for the investigation of Sciaccarello wine concept. J. Int. Sci. Vigne Vin. 2004, 38, 147-154. [CrossRef]

64. Ballester, J.; Dacremont, C.; Le Fur, Y.; Etiévant, P. The role of olfaction in the elaboration and use of the Chardonnay wine concept. Food Qual. Prefer. 2005, 16, 351-359. [CrossRef]

65. Schüttler, A.; Friedel, M.; Jung, R.; Rauhut, D.; Darriet, P. Characterizing aromatic typicality of riesling wines: Merging volatile compositional and sensory aspects. Food Res. Int. 2015, 69, 26-37. [CrossRef]

66. Moio, L.; Schlich, P.; Issanchou, S.; Etievant, P.X.; Feuillat, M. Description de la typicité aromatique de vins de Bourgogne issus du cépage Chardonnay. J. Int. Sci. Vigne Vin. 1993, 27, 179-189. [CrossRef]

67. Garrido-Bañuelos, G.; Ballester, J.; Buica, A.; Mihnea, M. Exploring the Typicality, Sensory Space, and Chemical Composition of Swedish Solaris Wines. Foods 2020, 9, 1107. [CrossRef]

68. Tempère, S.; Marchal, A.; Barbe, J.-C.; Bely, M.; Masneuf-Pomarede, I.; Marullo, P.; Albertin, W. The complexity of wine: Clarifying the role of microorganisms. Appl. Microbiol. Biotechnol. 2018, 102, 3995-4007. [CrossRef]

69. Lytra, G.; Tempère, S.; Le Floch, A.; De Revel, G.; Barbe, J.C. Study of sensory interactions among red wine fruity esters in a model solution. J. Agric. Food Chem. 2013, 61, 8504-8513. [CrossRef]

70. Ferreira, V. Volatile aroma compounds and wine sensory attributes. In Managing Wine Quality: Viticulture and Wine Quality; Reynolds, A.G., Ed.; Woodhead Publishing: Cambridge, UK, 2010; pp. 3-28.

71. Sánchez-Palomo, E.; Trujillo, M.; García Ruiz, A.; González Viñas, M.A. Aroma profile of malbec red wines from La Mancha region: Chemical and sensory characterization. Food Res. Int. 2017, 100, 201-208. [CrossRef]

72. Ferreira, V.; López, R.; Cacho, J.F. Quantitative determination of the odorants of young red wines from different grape varieties. J. Sci. Food Agric. 2000, 80, 1659-1667. [CrossRef]

73. Marais, J. Terpenes in the aroma of grapes and wines: A review. S. Afr. J. Enol. Vitic. 1983, 4, 49-58. [CrossRef]

74. Moyano, L.; Zea, L.; Morenio, J.; Medina, M. Analytical study of aromatic series in Sherry wines subjected to biological aging. J. Agric. Food Chem. 2002, 50, 7356-7361. [CrossRef]

75. Boidron, J.N.; Chatonnet, P.; Pons, M. Influence du bois sur certaines substances odorantes des vins. Connaiss. Vigne Vin. 1988, 22, 275-294. [CrossRef]

76. Culleré, L.; Escudero, A.; Cacho, J.; Ferreira, V. Gas Chromatography-Olfactometry and Chemical Quantitative Study of the Aroma of Six Premium Quality Spanish Aged Red Wines. J. Agric. Food Chem. 2004, 52, 1653-1660. [CrossRef]

77. Versini, G.; Schneider, R.; Carlin, S.; Depentori, D.; Nicolini, G.; Dalla Serra, A. Characterisation of Some Northern Italian Passiti-Wines through Aroma and Stable Isotope Analysis. In Proceedings of the 12th International Oenological Symposium, Montreal, QA, Canada, 29 May-2 June 1999; Lemperle, E., Ed.; International Association for Enology, Management and Wine Marketing: Breisach, Germany; pp. 544-571.

78. Janusz, A.; Capone, D.L.; Puglisi, C.J.; Perkins, M.; Elsey, G.M.; Sefton, M.A. (E)-1-(2,3,6-Trimethylphenyl)buta-1,3-diene: A potent grape-derived odorant in wine. J. Agric. Food Chem. 2003, 51, 7759-7763. [CrossRef]

79. Sacks, G.L.; Gates, J.M.; Ferry, F.X.; Lavin, E.H.; Kurtz, A.J.; Acree, T.E. Sensory Threshold of 1,1,6-Trimethyl-1,2dihydronaphthalene (TDN) and Concentrations in Young Riesling and Non-Riesling Wines. J. Agric. Food Chem. 2012, 60, 2998-3004. [CrossRef]

80. Etiévant, P.X. Volatile compounds in foods and beverages. In Wine; Maarse, H., Ed.; Marcel Dekker: New York, NY, USA, 1991; pp. 483-546.

81. Goniak, O.J.; Noble, A.C. Sensory study of selected volatile sulfur compounds in white wine. Am. J. Enol. Vitic. 1987, 38, 223-227. 
82. Mestres, M.; Busto, O.; Guasch, J. Analysis of organic sulfur compounds in wine aroma. J. Chromatogr. A 2000, 881, 569-581. [CrossRef]

83. Nguyen, D.-D.; Nicolau, L.; Dykes, S.I.; Kilmartin, P.A. Influence of microoxygenation on reductive sulfur off-odors and color development in a cabernet sauvignon wine. Am. J. Enol Vitic. 2010, 61, 457-464. [CrossRef]

84. Herbst-Johnstone, M.; Piano, F.; Duhamel, N.; Barker, D.; Fedrizzi, B. Ethyl propiolate derivatisation for the analysis of varietal thiols in wine. J.Chromatogr. A 2013, 1312, 104-110. [CrossRef]

85. Van Dool, H.V.D.; Kratz, P.D. A generalization of the retention index system including linear temperature programmed gasLiquid partition chromatography. J. Chromatogr. A 1963, 11, 463-471. [CrossRef]

86. Xia, J.; Sinelnikov, I.V.; Han, B.; Wishart, D.S. MetaboAnalyst 3.0—making metabolomics more meaningful. Nucleic Acids Res. 2015, 43, W251-W257. [CrossRef] 